\title{
Proteasome inhibition enhances the induction and impairs the maintenance of late-phase long-term potentiation
}

\author{
Chenghai Dong, ${ }^{1}$ Sudarshan C. Upadhya, ${ }^{1}$ Lan Ding, Thuy K. Smith, \\ and Ashok N. Hegde ${ }^{2}$ \\ Department of Neurobiology and Anatomy, Wake Forest University Health Sciences, Winston-Salem, North Carolina 27157, USA
}

\begin{abstract}
Protein degradation by the ubiquitin-proteasome pathway plays important roles in synaptic plasticity, but the molecular mechanisms by which proteolysis regulates synaptic strength are not well understood. We investigated the role of the proteasome in hippocampal late-phase long-term potentiation (L-LTP), a model for enduring synaptic plasticity. We show here that inhibition of the proteasome enhances the induction of L-LTP, but inhibits its maintenance. Proteasome inhibitor-mediated enhancement of the early part of L-LTP requires activation of NMDA receptors and the cAMP-dependent protein kinase. Augmentation of L-LTP induction by proteasome inhibition is blocked by a protein synthesis inhibitor anisomycin and is sensitive to the drug rapamycin. Our findings indicate that proteasome inhibition increases the induction of L-LTP by stabilizing locally translated proteins in dendrites. In addition, our data show that inhibition of the proteasome blocks transcription of brain-derived neurotrophic factor $(B D N F)$, which is a cAMP-responsive element-binding protein (CREB)-inducible gene. Furthermore, our results demonstrate that the proteasome inhibitors block degradation of ATF4, a CREB repressor. Thus, proteasome inhibition appears to hinder CREB-mediated transcription. Our results indicate that blockade of proteasome activity obstructs the maintenance of L-LTP by interfering with transcription as well as translation required to sustain L-LTP. Thus, proteasome-mediated proteolysis has different roles during the induction and the maintenance of L-LTP.
\end{abstract}

Several decades of investigation on synaptic plasticity underlying learning and memory have unearthed significant roles for posttranslational modifications such as phosphorylation in shortterm plasticity and for gene expression in causing long-lasting changes in synaptic strength (O'Dell et al. 1991; Kandel 2001; Deisseroth et al. 2003; Davis 2005; Mansuy and Shenolikar 2006). In recent years, a role for proteolysis by the ubiquitinproteasome pathway in synaptic plasticity has been discovered (Hegde and DiAntonio 2002; Murphey and Godenschwege 2002; Hegde 2004). In this pathway, proteins to be degraded are marked by covalent linkage to a small protein called ubiquitin for degradation by a proteolytic complex, the proteasome.

Previous studies on long-term facilitation in Aplysia, which underlies a simple form of long-term memory, revealed a role for ubiquitin-proteasome-mediated degradation of the inhibitory regulatory subunit of cAMP-dependent protein kinase (PKA) (Hegde et al. 1993). Moreover, an enzyme of the ubiquitinproteasome pathway called ubiquitin C-terminal hydrolase (Apuch), which interacts with the proteasome, was found to be induced by serotonin (5-HT), the neurotransmitter that induces long-term facilitation. Ap-uch was found to be critical for induction of long-term facilitation (Hegde et al. 1997). Degradation of regulatory subunit of PKA suggested that the role of proteolysis is to remove inhibitory constraints on long-term synaptic plasticity (Hegde et al. 1997; Chain et al. 1999). This idea has also been strengthened by our investigation showing degradation of a CREB repressor during long-term facilitation in Aplysia (Upadhya et al. 2004). Other recent work, however, has provided evidence

\footnotetext{
'These authors contributed equally to this work.

${ }^{2}$ Corresponding author.

E-mail ahegde@wfubmc.edu; fax (336) 716-4534.

Article is online at http://www.learnmem.org/cgi/doi/10.1101//m.984508.
}

to the contrary, supporting the notion that the ubiquitinproteasome pathway imposes an inhibitory check on long-term synaptic plasticity (Zhao et al. 2003). It is quite likely that the role of the ubiquitin-proteasome pathway in synaptic plasticity is more complex than what was suggested by the previous studies. To address the roles of proteolysis in long-term synaptic plasticity, we have developed a hypothesis that the ubiquitinproteasome pathway is locally regulated in neurons and that the pathway plays different roles in different neuronal compartments (Hegde 2004). In support of this idea, we have found that proteasome activity in the synaptic terminal differs from that in the nucleus in the Aplysia nervous system and in the mouse brain. Also, proteasome activity is differentially regulated in the two compartments (Upadhya et al. 2006).

In this study, using late-phase long-term potentiation (LLTP) as a model system, we have tested the effects of proteasome inhibition on long-term synaptic plasticity using electrophysiological as well as molecular studies. Our studies revealed that proteasome inhibition enhances the induction, but impairs the maintenance of L-LTP.

\section{Results}

Proteasome inhibitors increase the early, induction part of L-LTP, but block the late maintenance part of L-LTP

We preincubated mouse hippocampal slices for $30 \mathrm{~min}$ with a specific irreversible proteasome inhibitor clasto lactacystin $\beta$ lactone (henceforth $\beta$-lactone; $25 \mu \mathrm{M}$ ) (Fenteany et al. 1995) and induced L-LTP with four trains of $100 \mathrm{~Hz}$ spaced $5 \mathrm{~min}$ apart. We also used another proteasome inhibitor, epoxomycin, which is structurally different from $\beta$-lactone. When we subjected the results to two-way ANOVA (repeated measures) with proteasome 
inhibitor treatment and time as factors, we found significant difference for both factors and interaction between them (treatment, $F_{(2,32)}=3.574 ; P<0.05$; time, $F_{(1,32)}=183.942 ; P<0.001$; interaction $\left.F_{(2,32)}=27.198 ; P<0.001\right)$. A post-hoc analysis revealed that $\beta$-lactone caused a significant increase in the early part of L-LTP (at $30 \mathrm{~min}$ : $\beta$-lactone: $231 \pm 17 \%, n=6$; control: $169 \pm 10 \% ; P<0.001 ; n=7$ ) (Fig. 1A). Our post-hoc analysis revealed similar results with epoxomycin (at $30 \mathrm{~min}$ : epoxomycin: $252 \pm 9 \%, n=6$; control: $169 \pm 10 \% ; n=7 ; P<0.001$ ) (Fig. 1A). Under our incubation conditions, $\beta$-lactone greatly inhibited
A

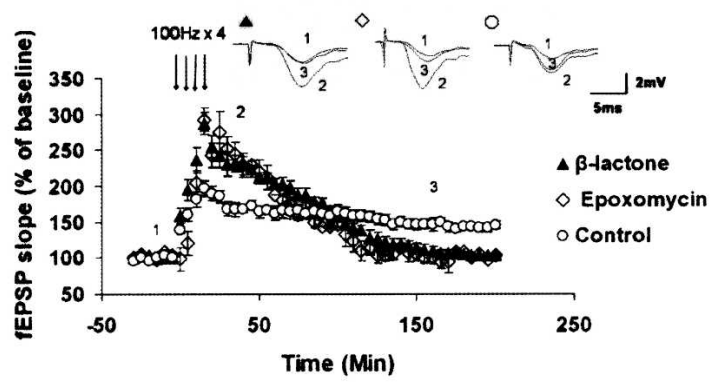

E

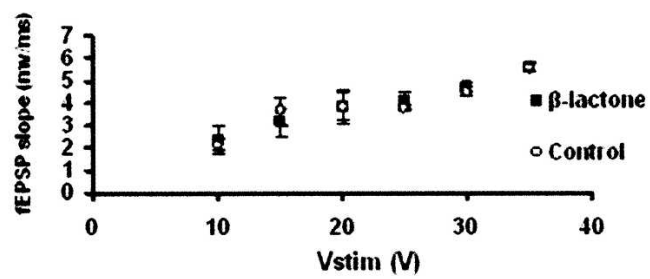

$\mathbf{F}$

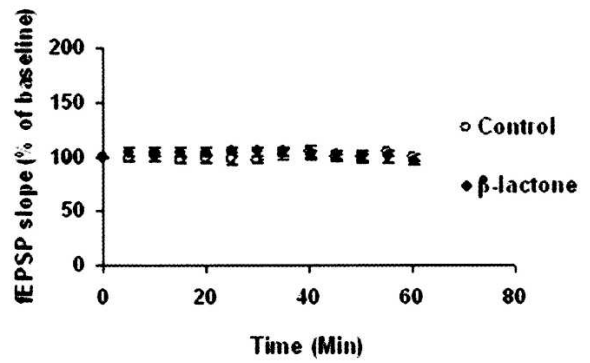

G

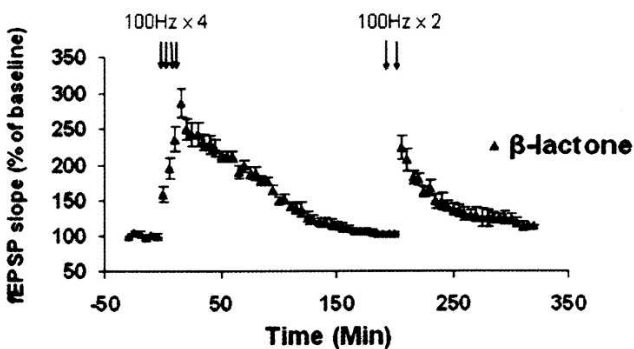

C

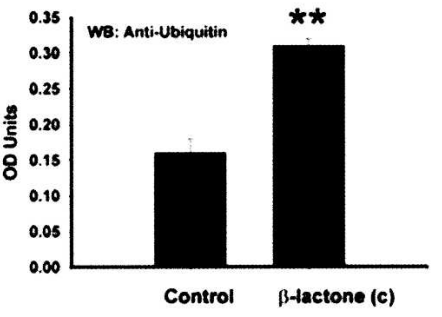

D

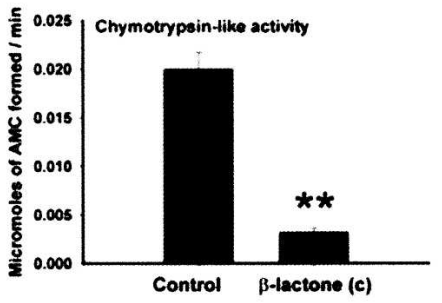

H

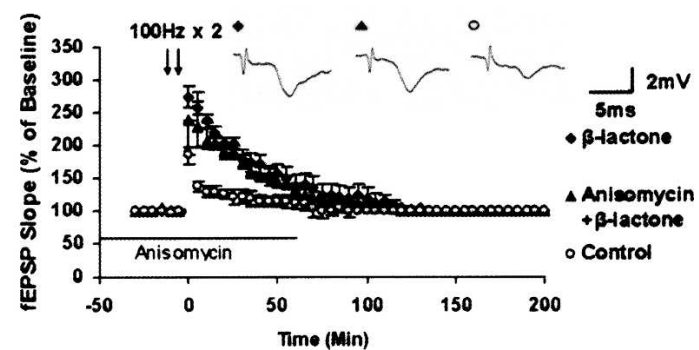

Figure 1. Effect of proteasome inhibitors on L-LTP and basal synaptic transmission, and biochemical measurements of proteasome inhibition. $(A)$ Enhancement of Ep-L-LTP with proteasome inhibitors $\beta$-lactone $(\boldsymbol{\Lambda})$ and epoxomycin $(\vartheta)$ relative to control $(\bigcirc)$. Both proteasome inhibitors significantly increase Ep-L-LTP $(P<0.001)$. Between 2 and $3 \mathrm{~h}$, enhancement of Ep-L-LTP begins to decay, and at $3 \mathrm{~h}$ is significantly less $(P<0.05)$ than the control L-LTP. The data were analyzed by two-way ANOVA with post-hoc Tukey test. (Inset) Representative traces taken at different time points $(1=$ baseline; $2=30 \mathrm{~min} ; 3=180 \mathrm{~min}$ ) for control and treatment with $\beta$-lactone and epoxomycin. (B) Proteasome inhibition in hippocampal slices treated with $\beta$-lactone [ $\beta$-lactone (c)] for 30 min causes accumulation of ubiquitin conjugates of proteins. (C) Quantification of ubiquitin conjugates indicates about twofold $\left(1.94 \pm 0.10 ;{ }^{*} P<0.01 ; n=5\right.$; $t$-test) accumulation of ubiquitinated proteins in $\beta$-lactone (c) slices relative to untreated slices. (D) $\beta$-lactone treatment of control slices [ $\beta$-lactone (c)] for 30 min causes significant decrease $\left(92 \pm 2 \%\right.$ inhibition; ${ }^{* *} P<0.01 ; n=5 ; t$-test) in catalytic activity of the proteasome as indicated by measurement of chymotrypsin-like activity of the proteasome. $(E)$ Normal basal synaptic transmission in $\beta$-lactone-treated hippocampal slices $(n=11)$ compared with untreated control $(n=10)$ slices. The graph shows input-output curves of fEPSP slope (mV/ms) versus stimulus at the Schaffer collateral pathway with and without $\beta$-lactone. ( $F$ ) Proteasome inhibition does not affect basal synaptic transmission, as shown by a second method. As an additional way to test the effect of proteasome inhibition on basal synaptic transmission, we continued the baseline recordings in slices pretreated with $\beta$-lactone or untreated (control) slices for $1 \mathrm{~h}$. No differences under the two conditions were observed (at 30 min, control: $97 \pm 2 \%$; $\beta$-lactone: $106 \pm 4 \%$; at 60 min, control: $101 \pm 5 \% ; \beta$-lactone: $100 \pm 3 \% ; n=6 ; P=0.183,0.337$, and 0.846 for treatment, time, and interaction, respectively; two-way ANOVA). (G) Induction of E-LTP after Ep-L-LTP decay. In the slices treated with $\beta$-lactone, E-LTP can be induced in $\beta$-lactone-treated slices $(n=3)$ after Ep-L-LTP decays back to baseline. These results indicate that the decay of Ep-L-LTP is not due to deterioration of slices because of $\beta$-lactone treatment. $(H)$ Enhancement of E-LTP with $\beta$-lactone. E-LTP is enhanced $(P<0.01)$ in $\beta$-lactone-treated slices $(\$)$ relative to untreated controls $(O)$. Prior treatment of slices with anisomycin $(\boldsymbol{\Lambda})$ has no significant $(P=0.700)$ effect on enhancement of E-LTP by $\beta$-lactone. (Inset) Representative traces taken at $30 \mathrm{~min}$. 
proteasome activity as judged by accumulation of ubiquitinated proteins and by direct measurement of catalytic activity (Fig. 1B-D). Pretreatment with $\beta$-lactone did not affect basal synaptic transmission (Fig. 1E,F). Henceforth, we refer to this early part of L-LTP as Ep-L-LTP for the sake of convenience and to distinguish it from the protein synthesis-independent early LTP called E-LTP that lasts for a short duration (Kelleher et al. 2004a).

We noticed that although L-LTP is initially increased, it decayed to baseline between 2 and $3 \mathrm{~h}$ after induction of LTP (at 3 h: $\beta$-lactone: $105 \pm 3 \%$; epoxomycin: $107 \pm 2 \%$; control: $143 \pm 3 \% ; P<0.05)$. We ascertained that the L-LTP decay was not due to deterioration of the slice. If the slice was in good condition, we would be able to induce E-LTP. We found that, indeed, we were able to induce E-LTP after L-LTP had decayed back to baseline (Fig. 1G).

Next, we tested the effect of $\beta$-lactone on E-LTP to determine whether proteasome inhibitors enhance short-term plasticity. We found that $\beta$-lactone increased E-LTP as well (at $30 \mathrm{~min}$ : control: $122 \% \pm 11 \%, n=5$; $\beta$-lactone: $179 \pm 14 \% ; n=6$; $P<0.01$ ) (Fig. 1H).

To obtain additional evidence for the effect of proteasome inhibition on L-LTP, we systematically tested the effect of different concentrations of $\beta$-lactone. Since the effective concentration of $\beta$-lactone against proteasome activity is in the micromolar range (Fenteany et al. 1995), we examined the effects of 1, 10, and $25 \mu \mathrm{M} \beta$-lactone. We also chose a theoretically noneffective concentration in the nanomolar range $(10 \mathrm{nM})$. Pretreatment with $\beta$-lactone significantly increased Ep-L-LTP with $10 \mu \mathrm{M}$ $(P<0.05)$ and $25 \mu \mathrm{M}(P<0.01)$ but not with $1 \mu \mathrm{M}(P=0.715)$ or $10 \mathrm{nM}(P=0.104)$ (at $30 \mathrm{~min}, \beta$-lactone at $25 \mu \mathrm{M}: 243 \pm 17 \% ; 10$ $\mu \mathrm{M}: 216 \pm 16 \% ; 1 \mu \mathrm{M}: 191 \pm 5 \% ; 10 \mathrm{nM}: 172 \pm 9 \% ; n=6$; control: $169 \pm 10 \% ; n=7)$. We found that $\beta$-lactone significantly decreased the later part of L-LTP with $25 \mu \mathrm{M}(P<0.001), 10 \mu \mathrm{M}$ $(P<0.01)$, but not with $1 \mu \mathrm{M}(P=0.208)$ or $10 \mathrm{nM}(P=0.751)$ (Fig. 2A).

To test whether the effect of proteasome inhibition on L-LTP is independent of the way in which LTP is measured, we carried out whole-cell recordings on hippocampal pyramidal neurons with or without prior $\beta$-lactone treatment. EPSC amplitude was enhanced after LTP induction and decreased by $2 \mathrm{~h}$ (at $30 \mathrm{~min}$ : $\beta$-lactone: $220 \pm 9 \%$; control: $179 \pm 6 \% ; P<0.001 ; n=6$; at $2 \mathrm{~h}$ : $\beta$-lactone: $120 \pm 8 \%$; control: $163 \pm 8 \% ; P<0.001 ; n=6$ ) (Fig. 2B). Next, we tested the effect of proteasome inhibition on L-LTP using a different protocol of LTP induction, the theta-burst protocol (TBP) which is thought to mimic the theta wave, the rhythm of hippocampal neurons in awake, behaving animals (Bland 1986). TBP has been shown to induce L-LTP (Nguyen and Kandel 1997). We observed significant increase in Ep-L-LTP and a decrease in the late part of L-LTP with TBP (at $30 \mathrm{~min}, \beta$ lactone: $226 \pm 10 \%$; control: $185 \pm 10 \%$; $P<0.001$; at $3 \mathrm{~h}, \beta$ lactone: $104 \pm 4 \%$; control: $161 \pm 4 \% ; P<0.001 ; n=6$ ) (Fig. 2C).

\section{Ep-L-LTP requires NMDA receptors and cAMP-dependent protein kinase (PKA)}

L-LTP has been shown to require NMDA receptor (Barco et al. 2002; Woo et al. 2003). If enhancement of Ep-L-LTP is due to the effect of proteasome inhibition on specific processes underlying L-LTP, $\beta$-lactone-mediated increase in Ep-L-LTP should be NMDA receptor dependent. Indeed, NMDA receptor antagonist AP5 (100 $\mu \mathrm{M})$, abolished the effect of $\beta$-lactone on Ep-L-LTP ( $\beta$-lactone: $231 \pm 17 \% ; \beta$-lactone + DL-AP5: $115 \pm 10 \% ; P<0.001 ; n=6$ ) (Fig. 3)

Previous studies have shown that L-LTP depends on PKA (Frey et al. 1993; Abel et al. 1997; Bozdagi et al. 2000; Nguyen and
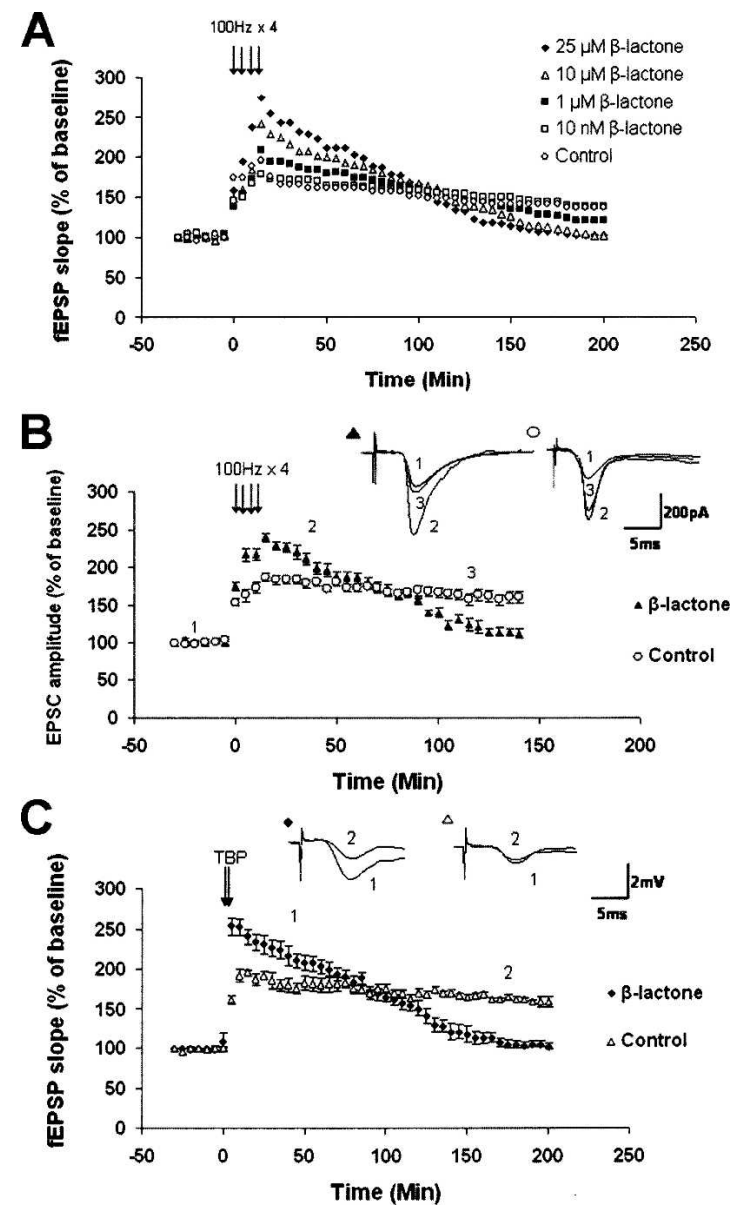

Figure 2. Additional evidence for the effect of proteasome inhibition on L-LTP. ( $A$ ) Concentration-dependent effect of $\beta$-lactone on Ep-L-LTP and late part of L-LTP. We observed significant enhancement of Ep-L-LTP relative to control with $10 \mu \mathrm{M}(P<0.05)$ and $25 \mu \mathrm{M}(P<0.01)$, but not with $1 \mu \mathrm{M}(P=0.715)$ or $10 \mathrm{nM}(P=0.104)$. At $3 \mathrm{~h}$ we observed significant decrease in L-LTP with $25 \mu \mathrm{M}(P<0.001), 10 \mu \mathrm{M}(P<0.01)$, but not with1 $\mu \mathrm{M}(P=0.208)$ or $10 \mathrm{nM}(P=0.751) \beta$-lactone. Error bars from the graph have been removed for the sake of clarity in the illustration. $(B)$ Enhancement in Ep-L-LTP and inhibition of late part of L-LTP with $\beta$ lactone measured by whole-cell recording of CA1 pyramidal neurons. Mean EPSCs from untreated and $\beta$-lactone-treated slices after induction of L-LTP. Extent of LTP is significantly $(P<0.001)$ higher at $30 \mathrm{~min}$ in $\beta$-lactone-treated slices compared with untreated controls. At $2 \mathrm{~h}$, extent of LTP is significantly $(P<0.001)$ lower in $\beta$-lactone-treated slices compared with controls. (Inset) Representative EPSCs from neurons from untreated and $\beta$-lactone-treated slices ( 1 = baseline; $2=30 \mathrm{~min} ; 3=120$ min). (C) Proteasome inhibition enhances L-LTP induced by theta burst protocol (TBP). L-LTP was induced with or without pretreatment with $\beta$-lactone using TBP. Significant enhancement of Ep-L-LTP $(P<0.001)$ and inhibition of maintenance $(P<0.001)$ part of L-LTP were observed. (Inset) Representative traces taken at different time points $(1=30 \mathrm{~min}$; $2=180 \mathrm{~min}$ ) for control and treatment with $\beta$-lactone.

Woo 2003). We tested whether the enhancement of Ep-L- LTP by $\beta$-lactone requires PKA. We observed that in the presence of PKA inhibitor KT5720, $\beta$-lactone-mediated increase in Ep-L-LTP was greatly reduced $(\beta$-lactone + KT5720: $134 \pm 11 \% ; P<0.001$; $n=5$ ) (Fig. 3). We also tested another highly specific and potent PKA inhibitor, a peptide corresponding to amino acids 14-22 of PKI (Walsh and Glass 1991), an endogenous PKA inhibitor. We used $\mathrm{PKI}_{14-22}$ that has been myristoylated at the $\mathrm{N}$ terminus to render it membrane permeant (myristoylated $\mathrm{PKI}_{14-22}$ amide; henceforth referred to as myristoylated PKI). Myristoylated PKI has been used to inhibit PKA in many cell types, including neu- 


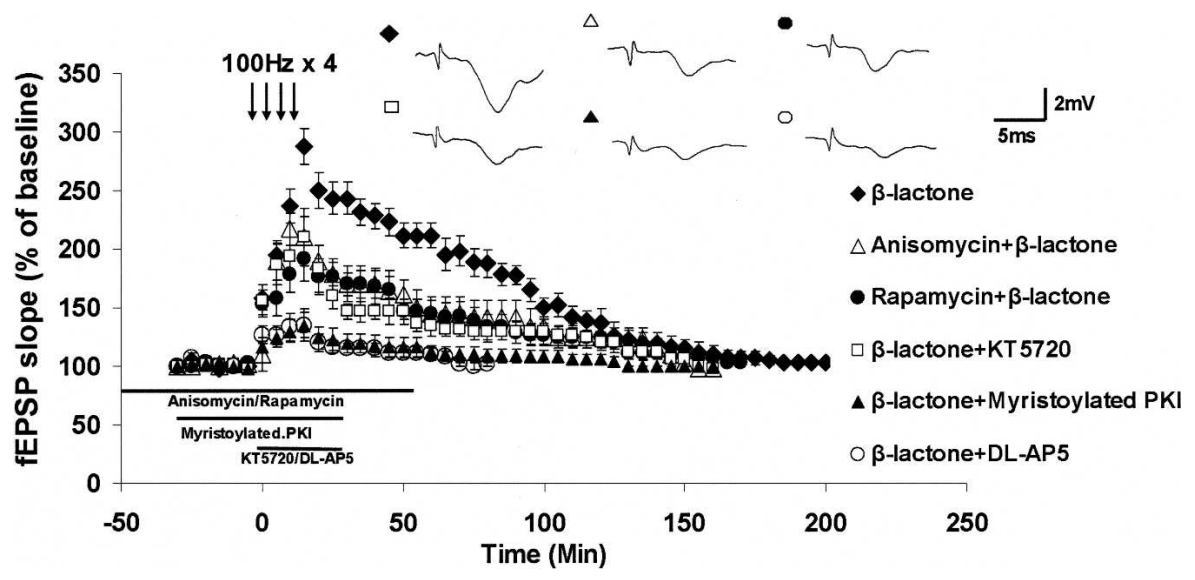

Figure 3. Characteristics of $\beta$-lactone-enhanced Ep-L-LTP. Dependence on NMDA receptors: Inclusion of NMDA receptor antagonist DL-AP5 $(n=6)$ in the bath almost completely $(P<0.001)$ abolishes Ep-L-LTP compared with $\beta$-lactone-treatment alone. Statistical analysis was by one-way ANOVA. (Inset) Representative traces taken at $30 \mathrm{~min}$. Dependence on PKA: Perfusion of the PKA inhibitor KT5720 in the bath for 30 min significantly $(P<0.001)$ reduces Ep-L-LTP in $\beta$-lactone-treated slices compared with $\beta$-lactone-treatment alone. Treatment of slices with myristoylated PKI also $(P<0.001)$ significantly decreases Ep-L-LTP. Inhibition by anisomycin: Treatment of slices with anisomycin prior to $\beta$-lactone treatment significantly $(P<0.01)$ diminishes the magnitude of Ep-L-LTP relative to $\beta$-lactone treatment alone. Inhibition by rapamycin: Rapamycin pretreatment also significantly $(P<0.01)$ reduces the $\beta$ lactone-enhanced Ep-L-LTP compared with $\beta$-lactone treatment alone.

rons (Muniz et al. 1997; Smith et al. 2005). We found that myristoylated PKI also significantly inhibited $\beta$-lactone-mediated enhancement of Ep-L-LTP $(\beta$-lactone + myristoylated PKI: $120 \pm 8 \% ; P<0.001 ; n=6$ ) (Fig. 3).

\section{Enhancement of Ep-L-LTP by $\beta$-lactone depends on protein synthesis}

The early part of L-LTP depends on translation of pre-existing mRNAs, whereas the late part L-LTP depends on transcription and translation (Frey et al. 1988, 1996). The time course of EpL-LTP appears to correspond to the translation-dependent, early part of L-LTP (Kelleher et al. 2004b). Therefore, we hypothesized that $\beta$-lactone enhances Ep-L-LTP by preventing the degradation of proteins synthesized from pre-existing mRNAs during the early phase of L-LTP. Hence, if we inhibited protein synthesis, $\beta$-lactone's effect should be abrogated or greatly diminished.

To test our hypothesis, we treated the slices with anisomycin $(25 \mu \mathrm{M})$ for $1 \mathrm{~h}$ prior to 30 -min incubation with $\beta$-lactone (25 $\mu \mathrm{M}$ final). Under these conditions, Ep-L-LTP was much lower compared with $\beta$-lactone alone (anisomycin $+\beta$-lactone: $145 \pm 14 \% ; P<0.01 ; n=6$ ) (Fig. 3). Thus, enhancement of EpL-LTP by $\beta$-lactone depends on protein synthesis just as L-LTP does. In contrast, our data indicate that the increase in E-LTP does not depend on protein synthesis (see Fig. 1H). We observed E-LTP to the same extent with $\beta$-lactone and anisomycin $+\beta$ lactone (at $30 \mathrm{~min}$; control: $122 \pm 11 \%$, $\beta$-lactone: $179 \pm 14 \%$; anisomycin $+\beta$-lactone: $167 \pm 11 \% ; n=6$; at $1 \mathrm{~h}$, control: $111 \pm 7 \%$; $\beta$-lactone: $139 \pm 13 \%$; anisomycin $+\beta$-lactone: $133 \pm 8 \% ; n=6$; $\beta$-lactone compared with control, $P<0.01$; anisomycin $+\beta$-lactone compared with control, $P<0.05 ; \beta$ lactone compared with anisomycin $+\beta$-lactone, $P=0.700$; Posthoc analysis after two-way ANOVA). Thus, the results show that $\beta$-lactone-mediated augmentation of Ep-L-LTP, but not increase in E-LTP, depends on protein synthesis.

Protein synthesis during the induction part of L-LTP is known to occur through translation of pre-existing mRNAs, a critical portion of which occurs in dendrites (Blitzer et al. 2005). Translation of dendritic mRNAs occurs through a signaling pathway mediated by a kinase called mammalian target of rapamycin
(mTOR) owing to its inhibition by rapamycin (Gingras et al. 2001). Previous studies have shown that rapamycin inhibits the induction of L-LTP (Tang et al. 2002; Cammalleri et al. 2003). To test whether the rapamycin-sensitive signaling pathway plays a role in Ep-L-LTP, we preincubated the slices with rapamycin $(1 \mu \mathrm{M})$ for $1 \mathrm{~h}$ and then treated the slices with $\beta$-lactone $(25 \mu \mathrm{M})$. We found that pretreatment with rapamycin significantly reduced Ep-L-LTP compared with $\beta$-lactone treatment alone (rapamycin $+\beta$-lactone: $145 \pm 16 \% ; P<0.01 ; n=6$ ) (Fig. 3). Thus, $\beta$-lactone-mediated enhancement of Ep-L-LTP is dependent on translation of pre-existing mRNAs part of which may occur in dendrites.

\section{Proteasome inhibition increases \\ Ep-L-LTP in isolated dendrites}

We hypothesized that enhancement of Ep-L-LTP by $\beta$-lactone occurs through stabilization of locally translated proteins in dendrites. To test this idea directly, we carried out experiments with dendrites separated from the cell bodies of pyramidal neurons. We isolated the dendrites in the CA1 region by means of a surgical cut as shown in Figure 4A. We ascertained the efficacy of the incisions by the absence of population spikes in the cell body layer (above the cut) when the stratum radiatum (below the cut) was stimulated. Also, fEPSPs were absent in the stratum radiatum (below the cut) when basilar dendrites of the CA1 pyramidal neurons (in the layer stratum oriens) were stimulated (data not shown). Surgical cuts such as these have been shown to be an effective way to physically sever dendrites from cell bodies (Woo and Nguyen 2003) Also, the protein synthesis dependence of dendritic LTP (Cracco et al. 2005) and L-LTP induction in severed dendrites have been demonstrated (Vickers et al. 2005).

After recovery of the surgically cut slices for $2 \mathrm{~h}$, we induced L-LTP with or without pretreatment with $\beta$-lactone. We observed the induction of L-LTP in isolated dendrites in untreated cut slices. In the $\beta$-lactone-treated cut slices, the extent of L-LTP induction was much higher compared with untreated cut slices (cut slices with $\beta$-lactone: $232 \pm 10 \%$; at $30 \mathrm{~min}$ after stimulation; $192 \pm 11 \%$ at $1 \mathrm{~h} ; n=6$; cut slices without $\beta$-lactone: $170 \pm 7 \%$ at $30 \mathrm{~min}$ after stimulation; $151 \pm 7 \%$ at $1 \mathrm{~h} ; n=5$; $P<0.05$ ) (Fig. 4B).

\section{Role of transcription in proteasome inhibitor-mediated effect on L-LTP}

Our experiments described above suggested a role for protein synthesis in enhancement of Ep-L-LTP. We tested whether this enhancement might be dependent on transcription. We found that increase in Ep-L-LTP was not prevented by transcription inhibitor actinomycin $\mathrm{D}(25 \mu \mathrm{M})($ at $30 \mathrm{~min}$, actinomycin $\mathrm{D}+\beta$ lactone: $256 \pm 16 \%$; $\beta$-lactone: $268 \pm 21 \% ; P=0.657, n=6$; at $1 \mathrm{~h}$, actinomycin $\mathrm{D}+\beta$-lactone: $226 \pm 17 \%$; $\beta$-lactone: $220 \pm 19 \% ; P=0.816 ; n=6$ ) (Fig. 5A). Blockade of the maintenance part of L-LTP with application of proteasome inhibitors suggested, however, that proteasome inhibition might hinder transcription required for the maintenance of L-LTP. If this is the case, the time window of sensitivity to proteasome inhibition might be similar to sensitivity of L-LTP to transcription inhibi- 
A

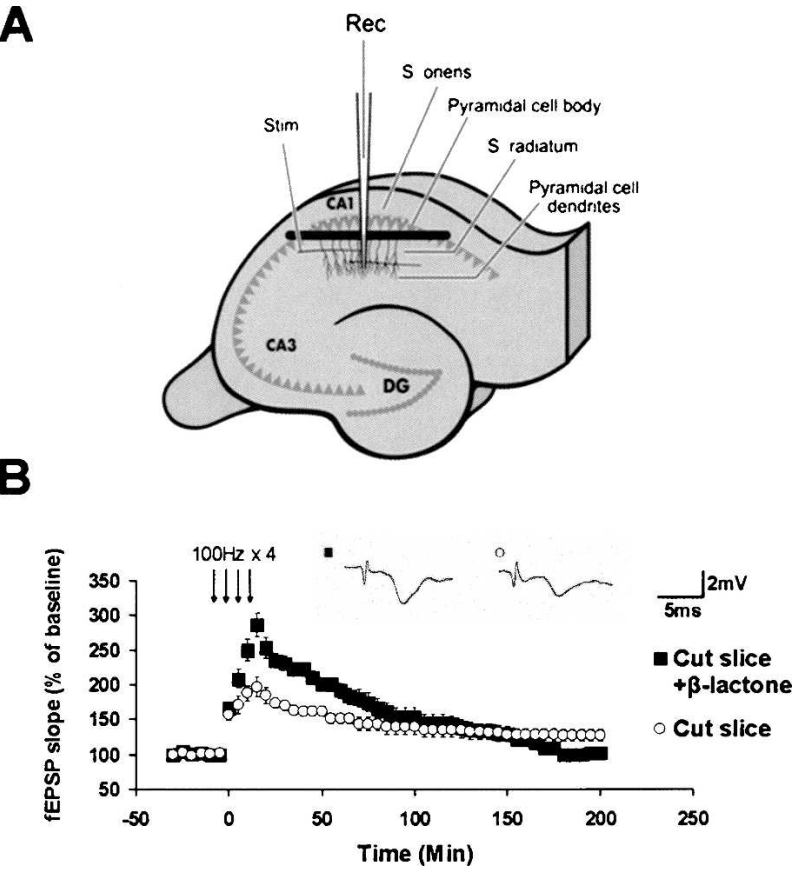

Figure 4. Proteasome inhibition in isolated dendrites enhances Ep-LLTP. (A) Schematic illustration of surgical isolation of dendrites. A cut (black bar) is made just below the pyramidal cell body layer in the CA1 region. Recording electrode (Rec) is placed in the dendritic layer of pyramidal cells. Position of the stimulation electrode (Stim), and the layers stratum radiatum and stratum oriens are also indicated. (DG) Dentate gyrus. (B) Treatment of slices with $\beta$-lactone significantly $(P<0.05)$ enhances Ep-L-LTP in dendrites relative to untreated cut slices. (Inset) Representative traces taken at $30 \mathrm{~min}$ for untreated cut slices and cut slices treated with $\beta$-lactone are shown.

tors. L-LTP can be inhibited by transcription inhibitors only during the first $2 \mathrm{~h}$ after the initiation of L-LTP (Nguyen et al. 1994). To test the time window, we used another proteasome inhibitor lactacystin (lactacystin is the precursor of $\beta$-lactone and has the same mode of action on the proteasome, but costs considerably less than $\beta$-lactone). When the data were analyzed by two-way ANOVA, (repeated measures) with lactacystin treatment and time as factors, we observed significant differences for both lactacystin treatment and time, and interaction between them (treatment, $F_{(1,14)}=4.736 ; P<0.05$; time, $F_{(1,14)}=30.639$; $P<0.001$; interaction $\left.F_{(1,14)}=11.927 ; P<0.01\right)$. Lactacystin enhances Ep-L-LTP and inhibits the maintenance of L-LTP similar to $\beta$-lactone (at $30 \mathrm{~min}$ : lactacystin, $227 \pm 11 \%$; control, $168 \pm 10 \% ; n=5 ; P<0.01 ;$ at $3 \mathrm{~h}$, lactacystin, $118 \pm 8 \%$; control, $146 \pm 10 ; n=5 ; P<0.05$ ) (Fig. 5B). Also, lactacystin does not affect basal synaptic transmission (Fig. 5C). Then we applied lactacystin to the bath $2 \mathrm{~h}$ after the start of L-LTP protocol. Application of lactacystin did not inhibit the maintenance of L-LTP if applied $2 \mathrm{~h}$ after the initiation of L-LTP (lactacystin: $158 \pm 6 \%$; control: $148 \pm 9 \%$ at $1 \mathrm{~h}$ after application; $n=6$; no significant difference $[P=0.34]$; and lactacystin: $142 \pm 5 \%$; control: $146 \pm 10 \%$ at $2 \mathrm{~h}$ after application; $n=6 ; P=0.62$ ) (Fig. 5D). These data suggest the possibility that proteasome inhibition blocks the maintenance of L-LTP by impeding transcription.

\section{Inhibition of proteasome blocks transcription of a CREB-inducible gene $B D N F$}

Our results indicated that proteasome inhibition is likely to inhibit the maintenance of L-LTP by blocking transcription. Some studies have shown a link between hippocampal L-LTP and gene
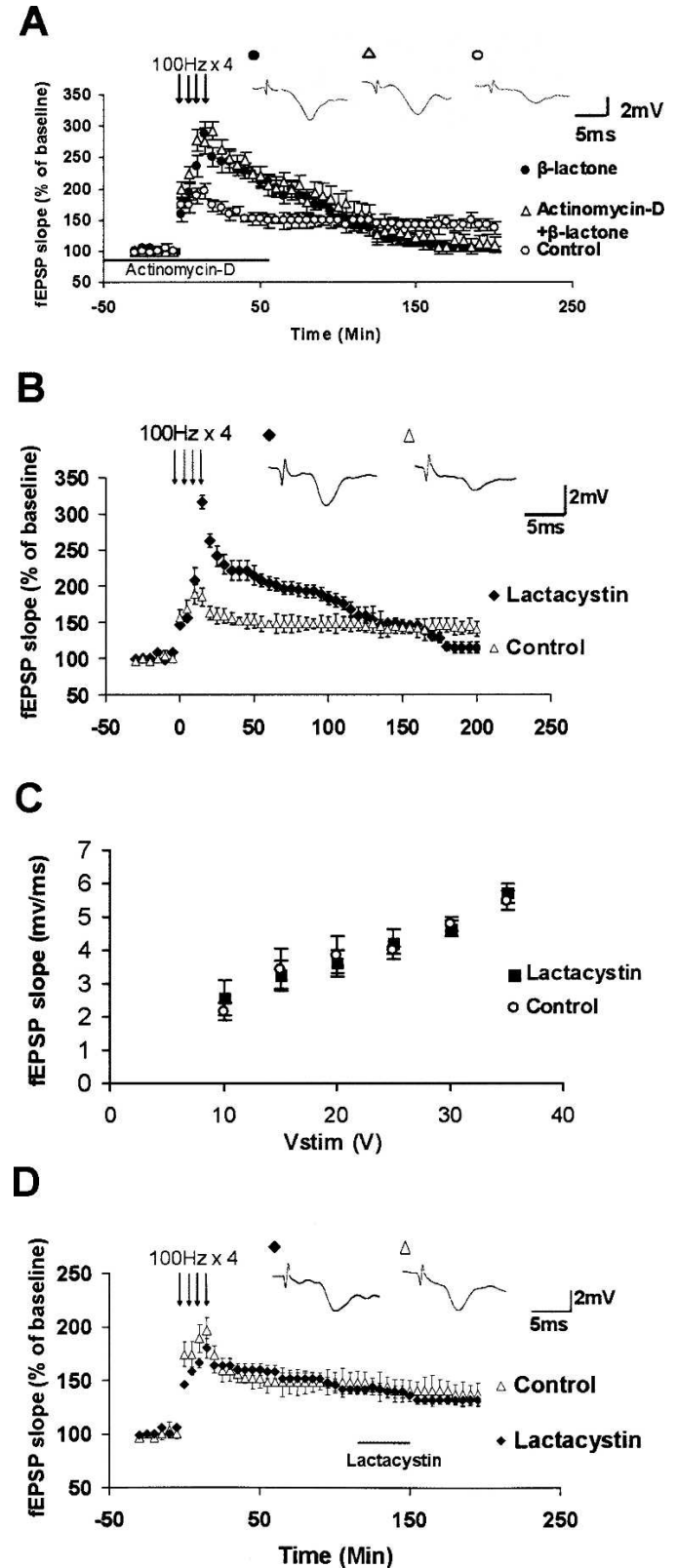

Figure 5. Proteasome inhibition enhances Ep-L-LTP without requiring transcription, but blocks L-LTP maintenance within a time window coinciding with that of transcription. (A) Enhancement of Ep-L-LTP does not require transcription. No significant difference in augmentation of Ep-LLTP was observed in the presence of transcription inhibitor actinomycin $\mathrm{D}(P=0.657)$. (Inset) Representative traces taken at $30 \mathrm{~min}$. (B) For testing the effect on L-LTP maintenance, we needed to use another proteasome inhibitor lactacystin. To ascertain that lactacystin has a similar effect on L-LTP compared with that of $\beta$-lactone, we preincubated the slices with lactacystin $(25 \mu \mathrm{M})$ and induced L-LTP. Lactacystin also significantly $(P<0.01)$ enhanced Ep-L-LTP, albeit to a slightly lesser extent than $\beta$ lactone. Overall, the effect of lactacystin was the same as that of $\beta$ lactone: At $30 \mathrm{~min}, \mathrm{Ep}-\mathrm{L}-\mathrm{LTP}$ was significantly $(P<0.01)$ higher compared with control L-LTP; lactacystin-enhanced Ep-L-LTP decayed between 2 and $3 \mathrm{~h}$, and at $3 \mathrm{~h}$ was significantly less $(P<0.05)$ than L-LTP in control slices. (Inset) Representative traces taken at $30 \mathrm{~min}$. (C) Normal basal synaptic transmission in lactacystin-treated hippocampal slices $(n=6)$ compared with untreated control $(n=6)$ slices. The graph shows input-output curves of fEPSP slope $(\mathrm{mV} / \mathrm{ms})$ versus stimulus at the Schaffer collateral pathway with and without lactacystin. $(D)$ Application of proteasome inhibitor lactacystin $2 \mathrm{~h}$ after tetanization does not block the maintenance of L-LTP. (Inset) Representative traces taken at $180 \mathrm{~min}$. 
expression mediated by the transcription factor cAMP-responsive element binding protein (CREB) (Impey et al. 1996; Moore et al. 1996; Barco et al. 2002). Therefore, we tested the effect of proteasome inhibition on transcription of BDNF (brain-derived neurotrophic factor) gene which contains cAMP-responsive elements (CREs) in its promoter sequence. Previous studies have shown that BDNF is a CREB-inducible gene (Tao et al. 1998). Furthermore, BDNF is rapidly induced during learning (Hall et al. 2000) and is necessary for the maintenance of L-LTP (Barco et al. 2005). Thus, $B D N F$ is an excellent candidate gene to test the effect of proteasome inhibition on CREB-mediated transcription.

We tested the effect of proteasome inhibition on BDNF induction using TBP to induce L-LTP. TBP has been shown to reliably induce BDNF mRNA (Lee et al. 2005). We found that BDNF was significantly $(P<0.01)$ induced by TBP in untreated slices and induction was inhibited $(P<0.01)$ when L-LTP was induced after $\beta$-lactone treatment (intensity units of BDNF RT-PCR product: control, $43.5 \pm 3.2$; L-LTP, $68.3 \pm 5.6 ; \beta$-lactone + L-LTP, $49.5 \pm 3.5, n=4$ ) (Fig. 6A,B).

Molecular studies after electrical stimulation of slices tend to be labor intensive and time consuming. Electrical stimulation modifies only a subset of the synapses, and therefore, detecting a molecular change may be difficult at times because of the background of unchanged synapses. Since chemical LTP (cLTP) modifies a large proportion (if not all) of the synapses, we can readily and routinely detect molecular changes with this method. cLTP induced by cAMP analogs or reagents that stimulate cAMP production is similar to electrically induced L-LTP (Frey et al. 1993; Makhinson et al. 1999; Otmakhov et al. 2004). We ascertained that our CLTP protocol induces LTP (extent of LTP at $60 \mathrm{~min}$, $181 \pm 10 \%, P<0.01$; at $120 \mathrm{~min}, 145 \pm 9.5 \%, P<0.01$; at 180 min, $138 \pm 8.2 \%, P<0.01 ; n=7$ ) (Fig. 6C). We induced cLTP (see Materials and Methods) with or without $\beta$-lactone $(25 \mu \mathrm{M})$ pretreatment and assessed the extent of BDNF mRNA induction using semiquantitative RT-PCR. We observed the induction of BDNF mRNA with cLTP and inhibition of induction in the presence of $\beta$-lactone (Fig. 6D). We quantified the induction of BDNF mRNA and inhibition of the induction using quantitative realtime PCR. BDNF mRNA was significantly induced $(3.8 \pm 0.61-$ fold relative to controls. $P<0.001 ; n=4$ ) with cLTP. The amount
A
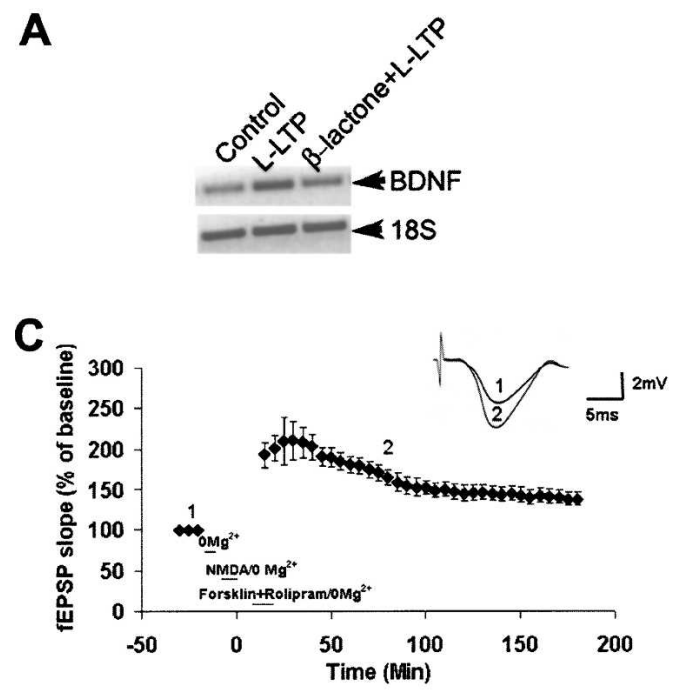

$\mathbf{F}$

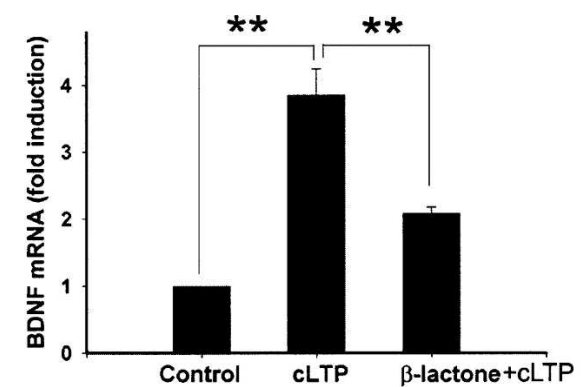

B

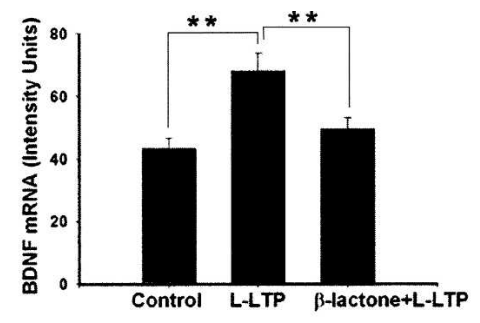

D

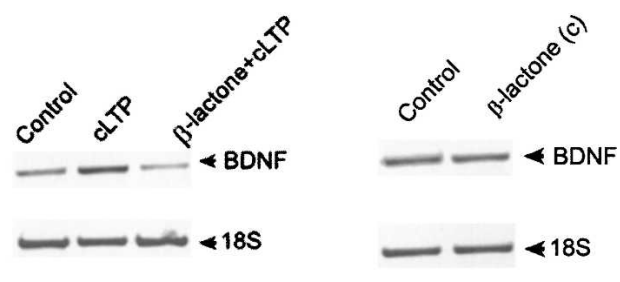

G

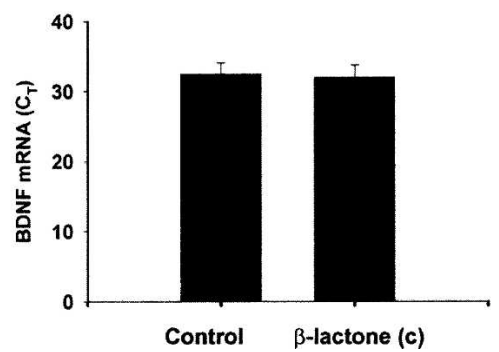

Figure 6. Molecular evidence for a role of the proteasome in transcription required for L-LTP. (A) L-LTP with theta-burst protocol induces BDNF mRNA and $\beta$-lactone inhibits BDNF induction. Semiquantitative RT-PCR shows induction of BDNF, a CREB-inducible gene, during L-LTP compared with control slices. Proteasome inhibitor $\beta$-lactone inhibits BDNF mRNA induction. 18S rRNA was used as control. (B) Quantification of BDNF mRNA induction and inhibition of induction by semiquantitative PCR showing significant induction of BDNF mRNA ( ${ }^{* *} P<0.01, n=4 ;$ one-way ANOVA) with L-LTP and significant inhibition ( $\left.{ }^{*} P<0.01 ; n=4\right)$ of BDNF mRNA induction with L-LTP after treatment with $\beta$-lactone. (C) Induction of CLTP with NMDA, forskolin, and rolipram. The figure shows induction of LTP with the CLTP protocol: Slices were treated with NMDA for 10 min, followed by forskolin + rolipram for 15 min. LTP induced is sustained up to $3 \mathrm{~h}(n=7)$. (D) CLTP induces BDNF mRNA and $\beta$-lactone inhibits BDNF induction. Semiquantitative RT-PCR shows induction of BDNF, a CREB-inducible gene, during CLTP, compared with control slices. Proteasome inhibitor $\beta$-lactone inhibits BDNF mRNA induction. 18S rRNA was used as control. $(E) \beta$-lactone treatment of control slices ( $\beta$-lactone (c)) has no appreciable effect on BDNF mRNA as measured by semiquantitative RT-PCR relative to untreated controls. ( $F$ ) Quantification of BDNF mRNA induction and inhibition of induction by quantitative real-time PCR showing significant ( $\left.{ }^{* *} P<0.001\right)$ induction of BDNF mRNA with CLTP and significant ( ${ }^{* *} P<0.01 ; n=4$; one-way ANOVA) inhibition of BDNF mRNA induction with CLTP after treatment with $\beta$-lactone. (G) Quantitative real-time PCR of BDNF mRNA shows no significant differences between control slices and control slices treated with the proteasome inhibitor [ $\beta$-lactone $(\mathrm{c})$ ] [threshold cycle $\left(\mathrm{C}_{\mathrm{T}}\right)$ in $\mathrm{control}$ : $32.48 \pm 1.55$; $\mathrm{C}_{\mathrm{T}}$ in $\beta$-lactone $(c): 31.98 \pm 1.76 ; P=0.620 ; n=4$. Also, comparison of fold induction calculated from $C_{\mathrm{T}}$ does not show any differences $[P=0.112]$ ). 
of BDNF mRNA was reduced significantly $(46.5 \pm 4.5 \%$ inhibition relative to cLTP; $P<0.01 ; n=4)$ but not completely in hippocampal slices treated with $\beta$-lactone prior to the induction of cLTP compared with slices that underwent cLTP induction without $\beta$-lactone treatment (Fig. 6F). Complete inhibition of BDNF mRNA induction likely requires a higher concentration of $\beta$-lactone. Treatment of control slices with $\beta$ lactone did not have any effect on BDNF expression (Fig. 6E,G).

\section{Degradation of a CREB repressor ATF4 during CLTP induction and stabilization of ATF4 by the proteasome inhibitor $\boldsymbol{\beta}$-lactone}

We hypothesized that inhibition of the late maintenance part of L-LTP is caused by blockade of degradation of a transcription repressor that blocks CREBmediated gene expression. This hypothesis is based on our observation that in Aplysia, a CREB repressor is a substrate for the ubiquitin-proteasome pathway (Upadhya et al. 2004). A CREB repressor that is known to block L-LTP is ATF4 (activating transcription factor 4 , which despite its name, is a repressor; it is also called CREB2) (Chen et al. 2003). Also, ATF4 is known to be degraded by the ubiquitin-proteasome pathway (Lassot et al. 2001).

We induced cLTP and prepared extracts of hippocampal slices and immunoblotted the extracts with anti-ATF4 antibody. We observed that 15 min after initiation of cLTP protocol, the quantity of ATF4 began to diminish and maximum decrease in ATF4 immunoreactivity was observed at $30 \mathrm{~min}$ relative to controls (at $30 \mathrm{~min}: 56 \pm 2.2 \%$ of ATF 4 was degraded relative to control [100\%]; $P<0.001 ; n=9$ ) (Fig. 7A). To test whether this decrease is a result of proteasomemediated degradation, we carried out the same experiment by incubating the slices with $\beta$-lactone. With $\beta$-lactone incubation, ATF4 immunoreactivity was significantly higher, indicating stabilization of ATF4 because of proteasome inhibition (ATF4 amount with cLTP $+\beta$ lactone was $180 \pm 19 \%$ relative to ATF4 amount with cLTP alone; $P<0.001 ; n=6$ ) (Fig. 7A,C). $\beta$-lactone by itself does not affect ATF4 protein levels in control slices (Fig. 7B,D). In addition, we observed an increase in ATF4-ubiquitin conjugates during CLTP. Consistent with our observation on ATF4 degradation, we found that the amount of ATF4-ubiquitin conjugates was maximal at $30 \mathrm{~min}$ and began to decrease by $45 \mathrm{~min}$. at $30 \mathrm{~min}$, quantity of ATF4-ubiquitin conjugates was significantly higher compared with the amount in control slices $(2.09 \pm 0.18$-fold relative to controls; $P<0.001 ; n=5$ ) (Fig. 7E,F).
A

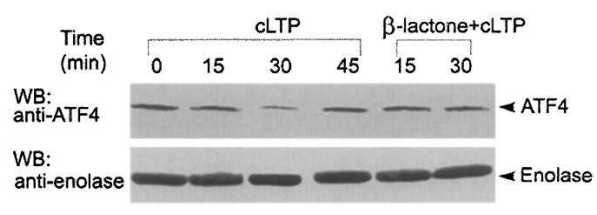

C

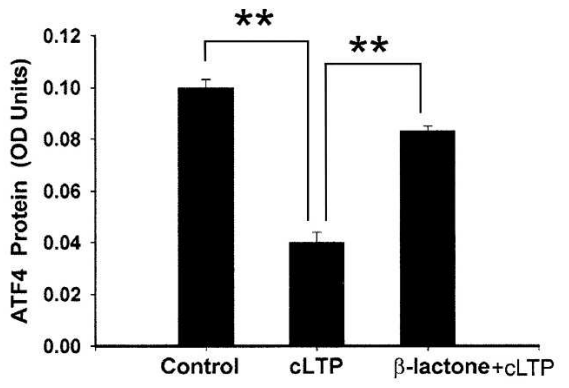

E

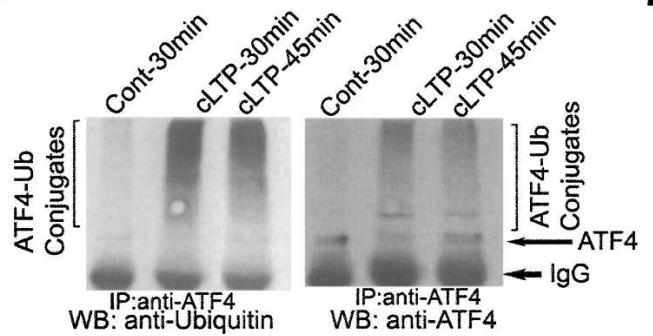

$\mathbf{F}$

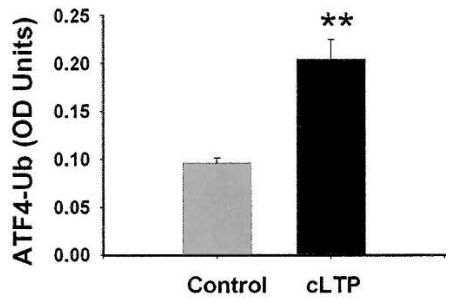

Figure 7. Degradation of ATF4 during CLTP and its stabilization by proteasome inhibition. $(A)$ Degradation of CREB repressor ATF4 during CLTP and inhibition of ATF4 degradation by $\beta$-lactone. Immunoblot experiments show degradation of ATF4 at 15 and 30 min after initiation of CLTP protocol. Degradation was inhibited when CLTP was induced after preincubation with the proteasome inhibitor $\beta$-lactone (see last two lanes at top labeled " $\beta$-lactone + CLTP"). ATF4 quantity was restored by 45 min, indicating that ATF4 degradation occurs during a narrow time window. (Bottom) The blot was stripped and reprobed with anti-enolase antibody to show equal loading of protein. (B) $\beta$-lactone treatment of control slices $[\beta$-lactone $(c)$ ] has no significant effect on ATF4 immunoreactivity. (C) Quantification of ATF4 degradation and inhibition of degradation by $\beta$-lactone. ATF4 quantity was significantly $\left({ }^{* *} P<0.001 ; n=9\right.$; one-way ANOVA) diminished $30 \mathrm{~min}$ after initiation of cLTP protocol and the protein was significantly ( ${ }^{\star *} P<0.001 ; n=6$; one-way ANOVA) stabilized when the CLTP protocol was carried out in the presence of $\beta$-lactone. (D) Quantification of ATF4 amounts (normalized to enolase) in untreated and $\beta$-lactone (c) slices reveals no significant difference [control: $0.24 \pm 0.0025$ OD units; $\beta$-lactone (c): $0.24 \pm 0.0028$ OD units; $P=0.537 ; n=4 ; t$-test]. ( $E$ ) ATF4 ubiquitination is increased during CLTP. ATF4 was immunoprecipitated (IP) from extracts of hippocampal slices with or without CLTP treatment and the immunoprecipitated material was analyzed by Western Blot (WB) with antiubiquitin antibodies (left). The blot was stripped and reprobed with anti-ATF4 antibodies (right). IgG band which shows because of reactivity to the secondary antibody is indicated. The high molecular weight components show both ubiquitin and ATF4 immunoreactivity, and therefore are ATF4ubiquitin (Ub) conjugates. The ATF4-Ub conjugates are increased in the CLTP samples at 30 min and begin to decrease at $45 \mathrm{~min}$. ( $F$ ) Quantification of ATF4-ubiquitin conjugates (at 30-min time point) by densitometry shows about twofold increase $\left(2.09 \pm 0.18\right.$-fold relative to controls; ${ }^{* *} P<0.001 ; n=5$; denst) in the amount of ATF4-ubiquitin conjugates in the cLTP samples.
-teritometry shows about twofold increase $2.09 \pm 0.18$-fold relative to

Extent of reversal of L-LTP inhibition with anisomycin application after $\boldsymbol{\beta}$-lactone treatment depends on the L-LTP induction protocol

Others have observed that when proteasome inhibitors and protein synthesis inhibitors are used simultaneously, L-LTP maintenance is not inhibited (Fonseca et al. 2006b). Our results show that when protein synthesis inhibitor anisomycin was applied prior to proteasome inhibition, enhancement of Ep-L-LTP was prevented and the later part of L-LTP was also blocked, consistent with the idea of protein synthesis requirement for Ep-L-LTP en- 
hancement (see Fig. 3). We think that the inhibition of the late part of L-LTP is because of build up of translation repressors. If this idea is correct, then preventing the accumulation of translation repressors with anisomycin treatment might rescue the late part of L-LTP. Therefore, we first treated the slices with $\beta$ lactone and then with anisomycin. We found that with 4-train protocol $(4 \times 100 \mathrm{~Hz})$, L-LTP maintenance was completely recovered (at $3 \mathrm{~h}, \beta$-lactone: $105 \pm 3.4 \%$; control: $143 \pm 2.8 \%$ $P<0.001, n=7 ; \beta$-lactone + anisomycin: $156 \pm 5 \%, P=0.319$ compared with control, $P<0.001$ compared with $\beta$-lactone alone; $n=6$ ) (Fig. 8A). In contrast, when L-LTP was induced with theta-burst protocol, we observed only partial recovery (at $3 \mathrm{~h}$, $\beta$-lactone: $104 \pm 4.2 \%$; control: $161 \pm 4.1 \% P<0.001, n=6$; $\beta$-lactone + anisomycin: $129 \pm 9.7 \% P<0.01$ compared with control, $P<0.05$ compared with $\beta$-lactone alone; $n=6$ ) (Fig. 8B).

\section{Discussion}

A role for the ubiquitin-proteasome pathway in synaptic plasticity has been shown in several model systems (Hegde and DiAntonio 2002; Murphey and Godenschwege 2002; Hegde 2004). The precise understanding of how this pathway contributes to alteration of synapses has been lacking. The gap in knowledge is especially evident with respect to the spatial and temporal functions of proteolysis in synaptic plasticity. Our studies have uncovered distinct temporal roles for the proteasome during the induction and the maintenance of L-LTP. Furthermore, our results hint at the possibility of disparate spatial roles for the proteasome during different phases of L-LTP.

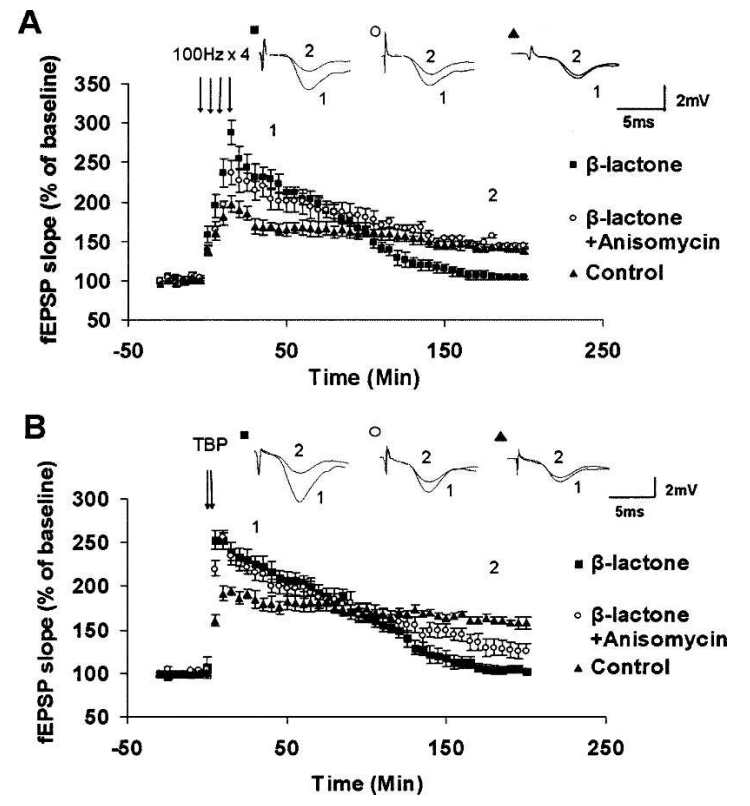

Figure 8. Recovery of L-LTP maintenance with anisomycin treatment after proteasome inhibition. (A) L-LTP was induced with $4 \times 100 \mathrm{~Hz}$ protocol by pretreatment with $\beta$-lactone alone or pretreatment with $\beta$ lactone followed by anisomycin treatment. Inhibition of the late part of L-LTP was prevented with $\beta$-lactone + anisomycin, and L-LTP is restored to control levels. (Inset) Representative traces taken at different time points $(1=30 \mathrm{~min} ; 2=180 \mathrm{~min})$ for control and, treatment with $\beta$ lactone and $\beta$-lactone + anisomycin. (B) L-LTP was induced with theta burst protocol (TBP) with pretreatment with $\beta$-lactone alone or pretreatment with $\beta$-lactone followed by anisomycin treatment. Inhibition of the late part of L-LTP was prevented to some extent and the recovery was partial. (Inset) Representative traces taken at different time points $(1=30$ $\min ; 2=180 \mathrm{~min}$ ) for control and treatment with $\beta$-lactone and $\beta$ lactone + anisomycin.
Proteasome constrains the early induction part of L-LTP Our studies have uncovered a novel role for the proteasome in L-LTP. The results show that proteasome inhibits the induction of L-LTP, as evidenced by a significant increase in the extent of L-LTP when slices are preincubated with proteasome inhibitors.

What might be the mechanism by which the proteasome constrains L-LTP? A likely possibility is that the proteasome limits the amount of newly synthesized proteins that can be utilized for plasticity. This notion is supported by our results showing that prior incubation of slices with anisomycin eliminates the effect of the proteasome inhibitor $\beta$-lactone. A major site of proteasome action in constraining the induction of L-LTP is probably in dendrites. In support of this idea, preincubation with rapamycin, which is known to inhibit translation of a subset of mRNAs (Jefferies et al. 1994; Terada et al. 1994), inhibits $\beta$ lactone-mediated enhancement of L-LTP. Local translation of rapamycin-sensitive mRNAs in dendrites plays a key role in the induction of L-LTP (Kelleher et al. 2004b; Sutton and Schuman 2006). Moreover, our experiments with isolated dendrites provide direct evidence for a role of the proteasome in stabilizing the proteins translated from pre-existing mRNAs in dendrites. How might proteasome inhibition enhance Ep-L-LTP? It is likely that in the initial stages, inhibition of proteasome activity stabilizes proteins that are positive regulators of plasticity. Substrates could include glutamate receptor subunits, aurora kinase, and postsynaptic density (PSD) proteins (Shank, GKAP, and AKAP79/150). GluR1 is synthesized in dendrites in an activity-dependent manner (Nayak et al. 1998) and Caenorhabditis elegans glutamate receptor GLR1 is a substrate for ubiquitination (Juo and Kaplan 2004). Degradation of the GluR1 subunits by the proteasome (Patrick et al. 2003) could limit the extent of synaptic transmission; therefore, blocking proteasome activity should increase synaptic strength through stabilization of GluR1. Aurora kinase phosphorylates CPEB (cytoplasmic polyadenylation elementbinding protein), which in turn is critical for translating CPE (cytoplasmic polyadenylation element) containing dendritic mRNAs such as that of CaM kinase II $\alpha$. Aurora kinase is known to be a substrate for the ubiquitin-proteasome pathway (Huang et al. 2002). Previous studies have found that stimulation of neuronal activity by incubation with bicuculine enhances the degradation of the PSD proteins and a proteasome inhibition stabilizes the proteins (Ehlers 2003). In addition to the substrates mentioned above, proteasome inhibition could stabilize components of the rapamycin signaling pathway, thus indirectly contributing to the increase in translation of proteins from preexisting mRNAs. For example, translation initiation factor eIF4E is known to be degraded by the ubiquitin-proteasome pathway (Murata and Shimotohno 2006).

The mechanisms underlying enhancement of Ep-L-LTP by proteasome inhibition may be different from those underlying proteasome inhibition-mediated enhancement of E-LTP. Although E-LTP requires protein synthesis when higher test frequencies of basal test stimulation are used (Fonseca et al. 2006a), we found that $\beta$-lactone-mediated enhancement of E-LTP did not depend on protein synthesis under our experimental conditions. Thus, the increase in E-LTP in our experiments might have resulted from stabilization of pre-existing proteins.

Our results suggest that proteasome inhibition leads to postsynaptic changes such as stabilization of newly synthesized proteins in dendrites. It is possible that proteasome inhibition causes presynaptic changes in the hippocampus such as modulation of transmitter release (Schulz et al. 1994; Isaac et al. 1996), although a recent study of cultured hippocampal neurons showed that proteasome inhibition caused an increase in the size of the recycling pool of synaptic vesicles without any effect on transmitter release probability (Willeumier et al. 2006). Detailed investiga- 
tions would be necessary to ascertain the extent of any presynaptic changes caused by proteasome inhibition in the hippocampus.

\section{Proteasome facilitates the late maintenance part of L-LTP}

Our data indicate that the proteasome plays a facilitatory role in the maintenance part of L-LTP. How might the proteasome facilitate the maintenance of L-LTP? One possible mechanism is through the positive regulatory role of the proteasome in transcription. Two lines of evidence support this idea. First, application of a proteasome inhibitor after the critical time window required for transcription did not inhibit the maintenance of L-LTP. Second, proteasome inhibition blocks transcription of BDNF, a CREB-regulated gene that is critical for the maintenance of L-LTP (Barco et al. 2005).

We think that there are at least two mechanisms by which proteasome inhibition can disrupt the maintenance of L-LTP. One is by preventing the degradation of transcription repressors. The other is by hindering late stages of translation in both dendrites and the cell body by stabilizing translation repressors.

How does inhibition of the proteasome block transcription? Our data show that a CREB repressor ATF4 is degraded during the induction of L-LTP, and ATF4 degradation is inhibited by proteasome inhibitor $\beta$-lactone. Therefore, it is likely that the proteasome aids in transcription by degrading the CREB repressor ATF4. Although we cannot rule out the possibility that the decrease in ATF4 during L-LTP induction resulted from its reduced translation (for example, stabilization of a phosphatase that negatively regulates eIF $2 \alpha$ phosphorylation, which increases ATF4 translation) (Costa-Mattioli et al. 2005, 2007), we believe that ATF4 degradation is likely to play a role in decreasing its amounts, because we observed an increase in ATF4 ubiquitination during cLTP. Although it remains to be proven, inhibition of ATF4 degradation might block transcription and the maintenance of LLTP.

Proteasome inhibition might also block degradation of other negative regulators of transcription. Alternative explanations for blockade of the maintenance of L-LTP by proteasome inhibition are plausible, however. For example, proteasome inhibition at dendrites caused by preincubation of the slices with $\beta$-lactone blocks signaling to the nucleus for initiation of transcription through CREB phosphorylation. Pretreatment of cultured cortical neurons for $24-48 \mathrm{~h}$ with a proteasome inhibitor caused a blockade of NMDA receptor coupling to CREB, as indicated by a decrease in CREB phosphorylation upon NMDA receptor stimulation. It has been suggested that the ubiquitinproteasome pathway plays a role in activity-dependent remodeling of the postsynaptic density and signaling to the nucleus (Ehlers 2003). It is also possible that proteasome has a direct role in transcription required for the maintenance of L-LTP.

Our results suggest that proteasome inhibition also prevents L-LTP maintenance by inhibiting translation. A translation repressor called Paip2 is known to be regulated by ubiquitinproteasome-mediated proteolysis (Yoshida et al. 2006). Also, in primary neuronal cultures proteasome inhibition has been shown to impair protein synthesis (Ding et al. 2006). Although, initially, proteasome inhibition can stabilize the newly translated proteins and enhance L-LTP induction, blockade of the proteasome could lead to a build-up of repressors that block translation in dendrites at about the end of the L-LTP induction phase, thus causing failure of L-LTP maintenance. Translation repressors could also accumulate in the cell body and inhibit cell-wide translation as well. Stabilization of translation repressor could be an important factor because our results showed L-LTP decay in the isolated dendrites. This argument is consistent with a previous report that showed that L-LTP can be induced and maintained in isolated dendrites (Vickers et al. 2005). The dendritic L-LTP observed by Vickers et al. was sensitive to translation inhibition.

\section{Comparison of the present investigations with other studies}

Although two previous studies have tested proteasome inhibition on LTP, they failed to discover enhancement of early L-LTP. One study on rat hippocampal slices reported inhibition of both early and late phases of LTP (Karpova et al. 2006). This study used a reagent called MG132 for inhibition of the proteasome. MG132 is not a highly specific proteasome inhibitor. MG132 has been known to strongly inhibit other proteases such as calpain and cathepsin B (Chain et al. 1999; Tang and Leppla 1999). Because calpain inhibition is known to block LTP (del Cerro et al. 1990; Denny et al. 1990), the results of experiments that just use MG132 are not strictly attributable to proteasome inhibition. The major conclusion of this study was that "LTP induction not only leads to a rapid increase in the rate of protein synthesis but also accelerates protein degradation via the proteasome system." Unlike this study, we have discovered a new effect of proteasome inhibition i.e., enhancement of Ep-L-LTP. Also, our detailed electrophysiological and molecular studies provide mechanistic explanations for the roles of proteasome during L-LTP. More importantly, our results show differential local roles for the proteasome during LTP, the induction and the maintenance, which provides a novel insight into the function of the proteasome in synaptic plasticity.

Another study reported the disruptive effect of proteasome inhibition on L-LTP maintenance in rat hippocampal slices without any effect on the induction phase of L-LTP (Fonseca et al. 2006b). We think the main reason that the investigators of the study failed to discover the enhancement of the early phase of L-LTP with proteasome inhibition is because they used nanomolar concentrations of lactacystin and epoxomycin. Numerous studies, including the one cited in the above-mentioned study (Dick et al. 1996), have established that micromolar concentration of lactacystin is required for efficient proteasome inhibition. All three catalytic activities of the proteasome are inhibited only with $100 \mu \mathrm{M}$ lactacystin or $50 \mu \mathrm{M} \beta$-lactone (Fenteany et al. 1995). Also, studies of proteasome substrates in neurons and other cell types have used 10-20 $\mathrm{MM}$ lactacystin (Ehlers 2003; Zhao et al. 2003), and studies on isolated nervous tissue have used $50 \mu \mathrm{M}$ lactacystin (Naidoo et al. 1999). Therefore, with nanomolar lactacystin, proteasome inhibition is not adequate to stabilize the positive regulators of L-LTP. In support of this idea, these authors report only a small inhibition (48\%) of the proteasome as measured by accumulation of protein-ubiquitin conjugates. The low degree of inhibition they observed was after $2 \mathrm{~h}$ incubation with the inhibitor, and therefore, during tetanization proteasome inhibition was likely to be even smaller. In contrast, we observed robust proteasome inhibition using the same incubation conditions that we use for our electrophysiological experiments (see Fig. 1B-D). Also, we have observed that synaptic proteasome has much higher activity (Upadhya et al. 2006) compared with other neuronal compartments. Hence, it is unlikely that Fonseca et al. (2006b) achieved any significant stabilization of positive regulators of L-LTP. In our studies, significant enhancement of Ep-L-LTP was observed only with $10 \mu \mathrm{M}$ or higher concentrations of $\beta$-lactone (see Fig. 2A). With respect to the effect of proteasome inhibition on L-LTP maintenance, it is likely that because of low concentrations of the proteasome inhibitors, the decay of L-LTP in the Fonseca et al. (2006b) study is gradual 
and the extent of inhibition of L-LTP maintenance is smaller than that observed in our study. Moreover, Fonseca et al. (2006b) used a protocol for L-LTP induction $(100 \mathrm{~Hz}$ for $1 \mathrm{sec}$, test frequency $0.1 \mathrm{~Hz}$ ) different from the standard L-LTP protocols (Nguyen et al. 1994; Nguyen and Kandel 1997; Kelleher et al. 2004a). It is not clear whether L-LTP induced by the protocol used by Fonseca et al. (2006b) requires transcription. Our investigations, in contrast, showed a deleterious effect of proteasome inhibition on L-LTP maintenance using L-LTP induction protocols that have been shown to depend on transcription (thetaburst protocol; cLTP with cAMP elevating reagents) (Frey et al. 1993; Nguyen and Kandel 1997). We also provide molecular evidence showing inhibition of a CREB-inducible gene BDNF with proteasome inhibition. Also, our observation on the CREB repressor ATF4 suggests a possible mechanistic explanation for blockade of L-LTP maintenance by proteasome inhibition.

In conclusion, our results provide evidence for different roles for the proteasome during the induction and the maintenance of L-LTP. Local ubiquitin-proteasome-mediated degradation may have broad implications for synaptic plasticity under physiological conditions, as well as synaptic dysfunction in many neurodegenerative diseases (Gong et al. 2006) with which abnormal proteolysis is associated.

\section{Materials and Methods}

\section{Animals}

Mice were obtained from Charles River and used for experiments using a protocol approved by the Institutional Animal Care and Use Committee of Wake Forest University Health Sciences.

\section{Extracellular recording}

Transverse hippocampal sections $(400 \mu \mathrm{m})$ from 6- to 12 -wk-old C57/BL6 male mice were prepared using a tissue chopper in an oxygenated and chilled artificial cerebrospinal fluid (ACSF) containing $125 \mathrm{mM} \mathrm{NaCl}, 3 \mathrm{mM} \mathrm{KCl}, 2.3 \mathrm{mM} \mathrm{CaCl}_{2}, 1.3 \mathrm{mM} \mathrm{MgCl}_{2}$, $25 \mathrm{mM} \mathrm{NaHCO}, 1.25 \mathrm{mM} \mathrm{NaH}_{2} \mathrm{PO}_{4}$, and $10 \mathrm{mM}$ glucose $(\mathrm{pH}$ 7.4). The slices were submerged at $32^{\circ} \mathrm{C}$ and superfused with ACSF $(1.5 \mathrm{~mL} / \mathrm{min})$ (Costa-Mattioli et al. 2005). All recordings were obtained from slices maintained at $32^{\circ} \mathrm{C}$. For recording of field excitatory postsynaptic potential (fEPSP), in the CA1 region of the hippocampus, a bipolar stimulating electrode was used to stimulate the Schaeffer collateral pathway while recording in the stratum radiatum. The stimulation intensity was adjusted to give $\sim 35 \%$ of the maximal fEPSP slope, and the baseline responses were recorded at this intensity. L-LTP was induced by giving four $100 \mathrm{~Hz}$ trains spaced $5 \mathrm{~min}$ apart. E-LTP was induced by giving two $100 \mathrm{~Hz}$ trains $20 \mathrm{sec}$ apart (Kelleher et al. 2004a). Theta-burst protocol to induce L-LTP was carried out as described by Lee et al. (2005). The stimulation protocol consisted of four pulses at 100 $\mathrm{Hz}$, with bursts repeated at $5 \mathrm{~Hz}$, and each tetanus including three 10-burst trains separated by $30 \mathrm{sec}$. The same stimulus was repeated after $5 \mathrm{~min}$ (Lee et al. 2005). The extent of LTP was expressed as percent increase relative to baseline in the fEPSP slope at different time points as stated in the figure legends. For experiments with the proteasome inhibitors $\beta$-lactone and epoxomycin, after recovery the slices were preincubated with the reagents in oxygenated ACSF for $30 \mathrm{~min}$. Inhibition of the proteasome by $\beta$-lactone and epoxomycin is irreversible, and therefore the inhibitory effect of these drugs cannot be washed out.

\section{Whole-cell recording}

Pyramidal cells in the CA1 region were recorded in the whole-cell mode using patch pipettes pulled from $1.5 \mathrm{~mm}$ borosilicate glass (5-6 $\mathrm{M} \Omega$ resistance). The microscope was equipped with infrared differential interference optics that allowed visualization of pyramidal neurons. The patch pipettes were filled with: $120 \mathrm{mM}$ potassium gluconate, $25 \mathrm{mM}$ HEPES, $10 \mathrm{mM} \mathrm{NaCl}, 5 \mathrm{mM} \mathrm{MgCl}$, $5 \mathrm{mM}$ K-ATP, $0.3 \mathrm{mM}$ Na-GTP, $0.2 \mathrm{mM}$ EGTA, and $2 \mathrm{mM}$ phos- phocreatine, and $10 \mathrm{U} / \mathrm{mL}$ creatine phosphokinase ( $\mathrm{pH} 7.35$ ). The osmolarity of the electrode solution was balanced to 294298 mOsm with $1 \mathrm{M}$ potassium gluconate. Whole-cell EPSCs in the pyramidal neurons were evoked by stimulating the Schaffer collateral pathway. Stimulation intensity was adjusted to $40 \%$ of maximal evoked amplitudes (test intensity). EPSCs were evoked at a stimulation rate of $0.033 \mathrm{~Hz}$. Baseline was recorded for 20 min at the test intensity. L-LTP was induced by switching to current-clamp mode and delivering four 1 -sec, $100-\mathrm{Hz}$ trains at a 5 -min intertrain interval as described previously (Duffy and Nguyen 2003).

\section{L-LTP in isolated dendrites}

We separated the dendrites by means of a surgical cut to the slice that has been shown to be effective (Frey and Morris 1997; Woo and Nguyen 2003 ;Cracco et al. 2005). We placed the hippocampal slices in ice-cold ACSF containing sucrose instead of $\mathrm{NaCl}$, and $\mathrm{MgCl}_{2}$ instead of $\mathrm{CaCl}_{2}$ (replacement chemicals were of same molarity), and made a cut below the cell body layer of CA1 region. The slices were then placed in normal ACSF and allowed to recover for $2 \mathrm{~h}$ before the experiment. L-LTP was induced as described previously (Vickers et al. 2005).

\section{Chemical LTP (cLTP) protocol}

We used cAMP elevating reagents forskolin and rolipram to chemically induce L-LTP (referred to all through the text as cLTP) for our molecular experiments. After recovery of the slices for $2 \mathrm{~h}$, we transferred them to $\mathrm{OMg}^{2+}$ ACSF containing NMDA (200 nM final) for $10 \mathrm{~min}$. We then transferred the slices to $0 \mathrm{Mg}^{2+} \mathrm{ACSF}$ containing forskolin $(50 \mu \mathrm{M}$ final $)+\operatorname{rolipram}(0.1 \mu \mathrm{M}$ final $)$ and incubated for $15 \mathrm{~min}$ and then transferred to normal ACSF (Otmakhov et al. 2004).

\section{Semiquantitative RT-PCR}

RT-PCR with increasing concentrations of cDNA and varying PCR cycle numbers was carried out to determine the linear range of amplification. The mid point of the linear range of the PCR amplification was used for subsequent RT-PCR experiments (Pernas-Alonso et al. 1999; Spencer and Christensen 1999). The PCR cycling conditions were: $94^{\circ} \mathrm{C}$ for $15 \mathrm{sec}, 58^{\circ} \mathrm{C}$ for $30 \mathrm{sec}$, and $72^{\circ} \mathrm{C}$ for $2 \mathrm{~min}$. The PCR products were analyzed by agarose gel electrophoresis, followed by staining with ethidium bromide. The PCR products were quantified by densitometry with Quantity One software (Bio-Rad Laboratories). Relative expression of the BDNF gene was determined by normalizing the expression values to the amounts of $18 \mathrm{~S}$ rRNA.

\section{Quantification of BDNF mRNA by real-time PCR}

After cLTP induction, total RNA was isolated from the mouse hippocampal slices and cDNA was prepared with random hexamers and StrataScript reverse Transcriptase (Stratagene) as per manufacturer's instructions. Expression of mRNA was measured by quantitative real-time PCR (ABI Prism 7700; Applied Biosystems) by using QuantiTect SYBR Green master mix (Qiagen, Inc.) and the primers 5'-GAAGGTTCGGCCCAACGA-3' (sense) and 5'-CCAGCAGAAAGAGTAGAGGAGGC-3' (antisense) specific for the BDNF coding region. These primers have been successfully used previously for quantification of BDNF mRNA in the CA1 region of the hippocampus (Barco et al. 2005). Genomic DNA contamination was ruled out by running PCR with RNA alone and by running PCR without cDNA template. Primer dimer formation was ruled out by checking the PCR product by running an agarose gel electrophoresis. Each independent sample was assayed in triplicate. The fluorescence signal from the SYBR Green dye was analyzed by using the ABI prism SDS software. Relative quantification of gene expression was performed using the comparative threshold $\left(\mathrm{C}_{\mathrm{T}}\right)$ method as described by the manufacturer (Applied Biosystems; User Bulletin 2) (Giulietti et al. 2001). Changes in BDNF mRNA expression level were calculated after normalization to $18 \mathrm{~S}$ rRNA. The primers for $18 \mathrm{~S}$ rRNA were $5^{\prime}-$ CGAAAGTCGGAGGTTCGAAGAC-3' (sense) and 5' - 
GGTGGTGCCCTTCCGTCAATT-3' (antisense). The ratios obtained after normalization are expressed as fold induction over corresponding control slices.

\section{Immunoblots and immunoprecipitation}

After the cLTP experiments, hippocampal slices were frozen immediately and homogenized in lysis buffer containing Tris- $\mathrm{HCl}$ buffer $(50 \mathrm{mM}, \mathrm{pH} 8.0)$ containing $\mathrm{NaCl}(150 \mathrm{mM})$, sodium deoxycholate $(0.5 \%, \mathrm{w} / \mathrm{v}), \mathrm{NP} 40(1 \%, \mathrm{v} / \mathrm{v})$, dithiothreitol $(50 \mathrm{mM})$, and protease inhibitor cocktail (Sigma) and were mixed with SDS-PAGE sample buffer and boiled for $4 \mathrm{~min}$. The samples were then incubated with benzonase nuclease (EMD Biosciences: 30 $\mathrm{U} / 100 \mu \mathrm{L}$ lysate) for $20 \mathrm{~min}$ at room temperature to digest the genomic DNA. Residual tissue fragments were removed by centrifugation and the supernatant was loaded on to $10 \%$ SDSpolyacrylamide gel and transferred to nitrocellulose membrane. ATF4 was detected by immunoblotting with anti-ATF4 antibody (Santa Cruz Biotechnologies, Inc.) and the same blot was stripped and reprobed with anti-enolase antibody (Santa Cruz) for verification of protein loading. We quantified ATF4 immunoreactivity by using densitometry on a Bio-Rad gel documentation system (Gel Doc 2000).

ATF4 was immunoprecipitated using anti-ATF4 antibody using Protein-A agarose beads by standard procedures (Harlow and Lane 1999). To test for ATF4-ubiquitin conjugates, the immunoprecipitated material was blotted and probed first with antiubiquitin antibody, then stripped, and reprobed with anti-ATF4 antibody.

\section{Proteasome activity assay}

The major catalytic activity (chymotrypsin-like activity) of the proteasome was measured using a fluoregenic substrate peptide N-succinyl-Leu-Leu-Val-Tyr-7-amino 4-methyl coumarin as described previously (Upadhya et al. 2006). Extracts from untreated slices or slices pretreated with $\beta$-lactone (for $30 \mathrm{~min}$ ) were used for proteasome activity measurements. Prevention of proteasome-mediated degradation should lead to accumulation of proteins conjugated with ubiquitin. Therefore, as an independent measure of proteasome inhibition by $\beta$-lactone, ubiquitinprotein conjugates were assayed using immunoblots with an anti-ubiquitin antibody that preferentially recognizes ubiquitinated proteins (Biomol). Ubiquitin-protein conjugates were quantified by densitometry using Quantity One 1-D Analysis Software (Bio-Rad). We measured the total intensity of all the pixels in the area of the lanes containing the ubiquitin conjugates and then divided the intensity by the area. We used average density (OD units) per unit area (square millimeters) for comparison between samples.

\section{Data analysis}

Data were analyzed by using two-way ANOVA (repeated measures) followed by a post-hoc Tukey test (pairwise multiple comparison procedures), while comparing multiple groups for treatment effect at different time points. Otherwise, multiple groups were compared by using one-way ANOVA followed by a post-hoc Tukey test (pairwise multiple comparison). For comparison between two groups, Student's $t$-test was used. The values are expressed as mean \pm standard error.

\section{Acknowledgments}

We thank Peter Nguyen (University of Alberta, Edmonton, Canada) and John Lisman (Brandeis University, Waltham, MA) for comments on an earlier version of the manuscript. We also thank Danny Winder (Vanderbilt University, Nashville, TN) for suggestions and guidance on LTP experiments and Dwayne Godwin (Wake Forest University) for technical advice. A.N.H is supported by a grant from the National Institute of Mental Health (MH060225).

\section{References}

Abel, T., Nguyen, P.V., Barad, M., Deuel, T.A., Kandel, E.R., and Bourtchouladze, R. 1997. Genetic demonstration of a role for PKA in the late phase of LTP and in hippocampus-based long-term memory. Cell 88: 615-626.

Barco, A., Alarcon, J.M., and Kandel, E.R. 2002. Expression of constitutively active CREB protein facilitates the late phase of long-term potentiation by enhancing synaptic capture. Cell 108: $689-703$.

Barco, A., Patterson, S., Alarcon, J.M., Gromova, P., Mata-Roig, M., Morozov, A., and Kandel, E.R. 2005. Gene expression profiling of facilitated L-LTP in VP16-CREB mice reveals that BDNF is critical for the maintenance of LTP and its synaptic capture. Neuron 48: $123-137$.

Bland, B.H. 1986. The physiology and pharmacology of hippocampal formation theta rhythms. Prog. Neurobiol. 26: 1-54.

Blitzer, R.D., Iyengar, R., and Landau, E.M. 2005. Postsynaptic signaling networks: Cellular cogwheels underlying long-term plasticity. Biol. Psychiatry 57: 113-119.

Bozdagi, O., Shan, W., Tanaka, H., Benson, D.L., and Huntley, G.W. 2000. Increasing numbers of synaptic puncta during late-phase LTP: $\mathrm{N}$-cadherin is synthesized, recruited to synaptic sites, and required for potentiation. Neuron 28: 245-259.

Cammalleri, M., Lutjens, R., Berton, F., King, A.R., Simpson, C., Francesconi, W., and Sanna, P.P. 2003. Time-restricted role for dendritic activation of the mTOR-p70S6K pathway in the induction of late-phase long-term potentiation in the CA1. Proc. Natl. Acad. Sci. 100: $14368-14373$.

Chain, D.G., Casadio, A., Schacher, S., Hegde, A.N., Valbrun, M. Yamamoto, N., Goldberg, A.L., Bartsch, D., Kandel, E.R., and Schwartz, J.H. 1999. Mechanisms for generating the autonomous cAMP-dependent protein kinase required for long-term facilitation in Aplysia. Neuron 22: 147-156.

Chen, A., Muzzio, I.A., Malleret, G., Bartsch, D., Verbitsky, M., Pavlidis, P., Yonan, A.L., Vronskaya, S., Grody, M.B., Cepeda, I., et al. 2003. Inducible enhancement of memory storage and synaptic plasticity in transgenic mice expressing an inhibitor of ATF4 (CREB-2) and C/EBP proteins. Neuron 39: 655-669.

Costa-Mattioli, M., Gobert, D., Harding, H., Herdy, B., Azzi, M., Bruno, M., Bidinosti, M., Ben, M.C., Marcinkiewicz, E., Yoshida, M., et al. 2005. Translational control of hippocampal synaptic plasticity and memory by the eIF2 $\alpha$ kinase GCN2. Nature 436: 1166-1173.

Costa-Mattioli, M., Gobert, D., Stern, E., Gamache, K., Colina, R., Cuello, C., Sossin, W., Kaufman, R., Pelletier, J., Rosenblum, K., et al. 2007. eIF $2 \alpha$ phosphorylation bidirectionally regulates the switch from short- to long-term synaptic plasticity and memory. Cell 129: $195-206$.

Cracco, J.B., Serrano, P., Moskowitz, S.I., Bergold, P.J., and Sacktor, T.C. 2005. Protein synthesis-dependent LTP in isolated dendrites of CA1 pyramidal cells. Hippocampus 15: 551-556.

Davis, R.L. 2005. Olfactory memory formation in Drosophila: From molecular to systems neuroscience. Annu. Rev. Neurosci. 28: 275-302.

Deisseroth, K., Mermelstein, P.G., Xia, H., and Tsien, R.W. 2003. Signaling from synapse to nucleus: The logic behind the mechanisms. Curr. Opin. Neurobiol. 13: 354-365.

del Cerro, S., Larson, J., Oliver, M.W., and Lynch, G. 1990. Development of hippocampal long-term potentiation is reduced by recently introduced calpain inhibitors. Brain Res. 530: 91-95.

Denny, J.B., Polan-Curtain, J., Ghuman, A., Wayner, M.J., and Armstrong, D.L. 1990. Calpain inhibitors block long-term potentiation. Brain Res. 534: 317-320.

Dick, L.R., Cruikshank, A.A., Grenier, L., Melandri, F.D., Nunes, S.L., and Stein, R.L. 1996. Mechanistic studies on the inactivation of the proteasome by lactacystin: A central role for clasto-lactacystin B-lactone. I. Biol. Chem. 271: 7273-7276.

Ding, Q., Dimayuga, E., Markesbery, W.R., and Keller, J.N. 2006. Proteasome inhibition induces reversible impairments in protein synthesis. FASEB J. 20: 1055-1063.

Duffy, S.N. and Nguyen, P.V. 2003. Postsynaptic application of a peptide inhibitor of cAMP-dependent protein kinase blocks expression of long-lasting synaptic potentiation in hippocampal neurons. J. Neurosci. 23: 1142-1150.

Ehlers, M.D. 2003. Activity level controls postsynaptic composition and signaling via the ubiquitin-proteasome system. Nat. Neurosci. 6: $231-242$

Fenteany, G., Standaert, R.F., Lane, W.S., Choi, S., Corey, E.J., and Schreiber, S.L. 1995. Inhibition of proteasome activities and subunit-specific amino-terminal threonine modification by lactacystin. Science 268: 726-731.

Fonseca, R., Nagerl, U.V., and Bonhoeffer, T. 2006a. Neuronal activity determines the protein synthesis dependence of long-term 
potentiation. Nat. Neurosci. 9: 478-480.

Fonseca, R., Vabulas, R.M., Hartl, F.U., Bonhoeffer, T., and Nagerl, U.V 2006b. A balance of protein synthesis and proteasome-dependent degradation determines the maintenance of LTP. Neuron 52: $239-245$.

Frey, U. and Morris, R.G. 1997. Synaptic tagging and long-term potentiation. Nature 385: 533-536.

Frey, U., Krug, M., Reymann, K.G., and Matthies, H. 1988. Anisomycin, an inhibitor of protein synthesis, blocks late phases of LTP phenomena in the hippocampal CA1 region in vitro. Brain Res. 452: $57-65$.

Frey, U., Huang, Y.Y., and Kandel, E.R. 1993. Effects of cAMP simulate a late stage of LTP in hippocampal CA1 neurons. Science 260: $1661-1664$

Frey, U., Frey, S., Schollmeier, F., and Krug, M. 1996. Influence of actinomycin D, a RNA synthesis inhibitor, on long-term potentiation in rat hippocampal neurons in vivo and in vitro. $J$. Physiol. 490: 703-711.

Gingras, A.C., Raught, B., and Sonenberg, N. 2001. Regulation of translation initiation by FRAP/mTOR. Genes \& Dev. 15: 807-826.

Giulietti, A., Overbergh, L., Valckx, D., Decallonne, B., Bouillon, R., and Mathieu, C. 2001. An overview of real-time quantitative PCR: Applications to quantify cytokine gene expression. Methods 25: $386-401$.

Gong, B., Cao, Z., Zheng, P., Vitolo, O.V., Liu, S., Staniszewski, A Moolman, D., Zhang, H., Shelanski, M., and Arancio, O. 2006. Ubiquitin hydrolase Uch-L1 rescues $\beta$-amyloid-induced decreases in synaptic function and contextual memory. Cell 126: 775-788.

Hall, J., Thomas, K.L., and Everitt, B.J. 2000. Rapid and selective induction of BDNF expression in the hippocampus during contextual learning. Nat. Neurosci. 3: 533-535.

Harlow, E. and Lane, D. 1999. Using antibodies a laboratory manual. Cold Spring Harbor Laboratory Press, Cold Spring Harbor, N.Y.

Hegde, A.N. 2004. Ubiquitin-proteasome-mediated local protein degradation and synaptic plasticity. Prog. Neurobiol. 73: 311-357.

Hegde, A.N. and DiAntonio, A. 2002. Ubiquitin and the synapse. Nat Rev. Neurosci. 3: 854-861.

Hegde, A.N., Goldberg, A.L., and Schwartz, J.H. 1993. Regulatory subunits of cAMP-dependent protein kinases are degraded after conjugation to ubiquitin: A molecular mechanism underlying long-term synaptic plasticity. Proc. Natl. Acad. Sci. 90: 7436-7440.

Hegde, A.N., Inokuchi, K., Pei, W., Casadio, A., Ghirardi, M., Chain, D.G., Martin, K.C., Kandel, E.R., and Schwartz, J.H. 1997. Ubiquitin C-terminal hydrolase is an immediate-early gene essential for long-term facilitation in Aplysia. Cell 89: 115-126.

Huang, Y.S., Jung, M.Y., Sarkissian, M., and Richter, J.D. 2002. $\mathrm{N}$-methyl-D-aspartate receptor signaling results in Aurora kinase-catalyzed CPEB phosphorylation and $\alpha$ CaMKII mRNA polyadenylation at synapses. EMBO J. 21: 2139-2148.

Impey, S., Mark, M., Villacres, E.C., Poser, S., Chavkin, C., and Storm, D.R. 1996. Induction of CRE-mediated gene expression by stimuli that generate long-lasting LTP in area CA1 of the hippocampus. Neuron 16: 973-982.

Isaac, J.T., Oliet, S.H., Hjelmstad, G.O., Nicoll, R.A., and Malenka, R.C. 1996. Expression mechanisms of long-term potentiation in the hippocampus. J. Physiol. 90: 299-303.

Jefferies, H.B., Reinhard, C., Kozma, S.C., and Thomas, G. 1994. Rapamycin selectively represses translation of the "polypyrimidine tract" mRNA family. Proc. Natl. Acad. Sci. 91: 4441-4445.

Juo, P. and Kaplan, J.M. 2004. The anaphase-promoting complex regulates the abundance of GLR-1 glutamate receptors in the ventral nerve cord of C. elegans. Curr. Biol. 14: 2057-2062.

Kandel, E.R. 2001. The molecular biology of memory storage: A dialogue between genes and synapses. Science 294: 1030-1038.

Karpova, A., Mikhaylova, M., Thomas, U., Knopfel, T., and Behnisch, T. 2006. Involvement of protein synthesis and degradation in long-term potentiation of Schaffer collateral CA1 synapses. $J$. Neurosci. 26: 4949-4955.

Kelleher III, R.J., Govindarajan, A., Jung, H.Y., Kang, H., and Tonegawa, S. 2004a. Translational control by MAPK signaling in long-term synaptic plasticity and memory. Cell 116: 467-479.

Kelleher III, R.J., Govindarajan, A., and Tonegawa, S. 2004b. Translational regulatory mechanisms in persistent forms of synaptic plasticity. Neuron 44: 59-73.

Lassot, I., Segeral, E., Berlioz-Torrent, C., Durand, H., Groussin, L., Hai T., Benarous, R., and Margottin-Goguet, F. 2001. ATF4 degradation relies on a phosphorylation-dependent interaction with the SCF( $\beta$ TrCP) ubiquitin ligase. Mol. Cell. Biol. 21: 2192-2202.

Lee, P.R., Cohen, J.E., Becker, K.G., and Fields, R.D. 2005. Gene expression in the conversion of early-phase to late-phase long-term potentiation. Ann. N. Y. Acad. Sci. 1048: 259-271.

Makhinson, M., Chotiner, J.K., Watson, J.B., and O'Dell, T.J. 1999.
Adenylyl cyclase activation modulates activity-dependent changes in synaptic strength and $\mathrm{Ca}^{2+} /$ calmodulin-dependent kinase II autophosphorylation. I. Neurosci. 19: 2500-2510.

Mansuy, I.M. and Shenolikar, S. 2006. Protein serine/threonine phosphatases in neuronal plasticity and disorders of learning and memory. Trends Neurosci. 29: 679-686.

Moore, A.N., Waxham, M.N., and Dash, P.K. 1996. Neuronal activity increases the phosphorylation of the transcription factor cAMP response element-binding protein (CREB) in rat hippocampus and cortex. J. Biol. Chem. 271: 14214-14220.

Muniz, M., Martin, M.E., Hidalgo, J., and Velasco, A. 1997. Protein kinase A activity is required for the budding of constitutive transpor vesicles from the trans-Golgi network. Proc. Natl. Acad. Sci. 94: $14461-14466$

Murata, T. and Shimotohno, K. 2006. Ubiquitination and proteasome-dependent degradation of human eukaryotic translation initiation factor 4E. J. Biol. Chem. 281: 20788-20800.

Murphey, R.K. and Godenschwege, T.A. 2002. New roles for ubiquitin in the assembly and function of neuronal circuits. Neuron 36: 5-8.

Naidoo, N., Song, W., Hunter-Ensor, M., and Sehgal, A. 1999. A role for the proteasome in the light response of the timeless clock protein. Science 285: 1737-1741.

Nayak, A., Zastrow, D.J., Lickteig, R., Zahniser, N.R., and Browning, M.D. 1998. Maintenance of late-phase LTP is accompanied by PKA-dependent increase in AMPA receptor synthesis. Nature 394: $680-683$.

Nguyen, P.V. and Kandel, E.R. 1997. Brief theta-burst stimulation induces a transcription-dependent late phase of LTP requiring cAMP in area CA1 of the mouse hippocampus. Learn. Mem. 4: 230-243.

Nguyen, P.V. and Woo, N.H. 2003. Regulation of hippocampal synaptic plasticity by cyclic AMP-dependent protein kinases. Prog. Neurobiol. 71: $401-437$.

Nguyen, P.V., Abel, T., and Kandel, E.R. 1994. Requirement of a critica period of transcription for induction of a late phase of LTP. Science 265: 1104-1107.

O'Dell, T.J., Hawkins, R.D., Kandel, E.R., and Arancio, O. 1991. Tests of the roles of two diffusible substances in long-term potentiation: Evidence for nitric oxide as a possible early retrograde messenger. Proc. Natl. Acad. Sci. 88: 11285-11289.

Otmakhov, N., Khibnik, L., Otmakhova, N., Carpenter, S., Riahi, S. Asrican, B., and Lisman, J. 2004. Forskolin-induced LTP in the CA1 hippocampal region is NMDA receptor dependent. J. Neurophysiol. 91: $1955-1962$.

Patrick, G.N., Bingol, B., Weld, H.A., and Schuman, E.M. 2003. Ubiquitin-mediated proteasome activity is required for agonist-induced endocytosis of GluRs. Curr. Biol. 13: 2073-2081.

Pernas-Alonso, R., Morelli, F., U.di, P., and Perrone-Capano, C. 1999. Multiplex semi-quantitative reverse transcriptase-polymerase chain reaction of low abundance neuronal mRNAs. Brain Res. Brain Res. Protoc. 4: 395-406.

Schulz, P.E., Cook, E.P., and Johnston, D. 1994. Changes in paired-pulse facilitation suggest presynaptic involvement in long-term potentiation. J. Neurosci. 14: 5325-5337.

Smith, W.B., Starck, S.R., Roberts, R.W., and Schuman, E.M. 2005. Dopaminergic stimulation of local protein synthesis enhances surface expression of GluR1 and synaptic transmission in hippocampal neurons. Neuron 45: 765-779.

Spencer, W.E. and Christensen, M.J. 1999. Multiplex relative RT-PCR method for verification of differential gene expression. Biotechniques 27: 1044-1050, 1052 .

Sutton, M.A. and Schuman, E.M. 2006. Dendritic protein synthesis, synaptic plasticity, and memory. Cell 127: 49-58.

Tang, G. and Leppla, S.H. 1999. Proteasome activity is required for anthrax lethal toxin to kill macrophages. Infect. Immun. 67: 3055-3060.

Tang, S.J., Reis, G., Kang, H., Gingras, A.C., Sonenberg, N., and Schuman, E.M. 2002. A rapamycin-sensitive signaling pathway contributes to long-term synaptic plasticity in the hippocampus. Proc. Natl. Acad. Sci. 99: 467-472.

Tao, X., Finkbeiner, S., Arnold, D.B., Shaywitz, A.J., and Greenberg, M.E. 1998. $\mathrm{Ca}^{2+}$ influx regulates BDNF transcription by a CREB family transcription factor-dependent mechanism. Neuron 20: 709-726.

Terada, N., Patel, H.R., Takase, K., Kohno, K., Nairn, A.C., and Gelfand, E.W. 1994. Rapamycin selectively inhibits translation of mRNAs encoding elongation factors and ribosomal proteins. Proc. Natl. Acad. Sci. 91: $11477-11481$

Upadhya, S.C., Smith, T.K., and Hegde, A.N. 2004. Ubiquitin-proteasome-mediated CREB repressor degradation during induction of long-term facilitation. J. Neurochem. 91: 210-219.

Upadhya, S.C., Ding, L., Smith, T.K., and Hegde, A.N. 2006. Differential regulation of proteasome activity in the nucleus and the synaptic terminals. Neurochem. Int. 48: 296-305. 
Vickers, C.A., Dickson, K.S., and Wyllie, D.J. 2005. Induction and maintenance of late-phase long-term potentiation in isolated dendrites of rat hippocampal CA1 pyramidal neurones. J. Physiol. 568: 803-813.

Walsh, D.A. and Glass, D.B. 1991. Utilization of the inhibitor protein of adenosine cyclic monophosphate-dependent protein kinase, and peptides derived from it, as tools to study adenosine cyclic monophosphate-mediated cellular processes. Methods Enzymol. 201: 304-316.

Willeumier, K., Pulst, S.M., and Schweizer, F.E. 2006. Proteasome inhibition triggers activity-dependent increase in the size of the recycling vesicle pool in cultured hippocampal neurons. J. Neurosci. 26: 11333-11341.

Woo, N.H. and Nguyen, P.V. 2003. Protein synthesis is required for synaptic immunity to depotentiation. J. Neurosci. 23: 1125-1132.
Woo, N.H., Duffy, S.N., Abel, T., and Nguyen, P.V. 2003. Temporal spacing of synaptic stimulation critically modulates the dependence of LTP on cyclic AMP-dependent protein kinase. Hippocampus 13: 293-300.

Yoshida, M., Yoshida, K., Kozlov, G., Lim, N.S., De, C.G., Pang, Z., Berlanga, J.J., Kahvejian, A., Gehring, K., Wing, S.S., et al. 2006. Poly(A) binding protein (PABP) homeostasis is mediated by the stability of its inhibitor, Paip2. EMBO J. 25: 1934-1944.

Zhao, Y., Hegde, A.N., and Martin, K.C. 2003. The ubiquitin proteasome system functions as an inhibitory constraint on synaptic strengthening. Curr. Biol. 13: 887-898.

Received February 27, 2008; accepted in revised form March 20, 2008. 


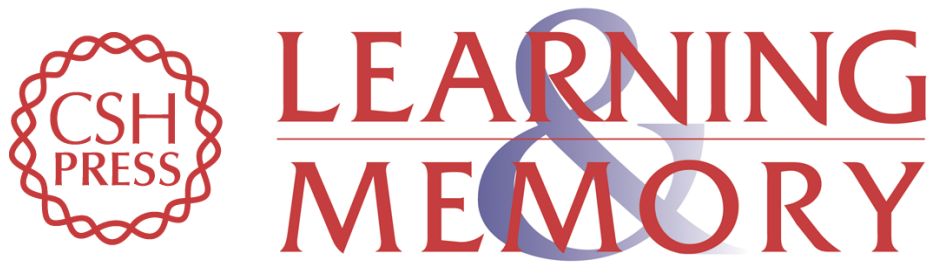

\section{Proteasome inhibition enhances the induction and impairs the maintenance of late-phase long-term potentiation}

Chenghai Dong, Sudarshan C. Upadhya, Lan Ding, et al.

Learn. Mem. 2008, 15:

Access the most recent version at doi:10.1101//m.984508

References This article cites 78 articles, 26 of which can be accessed free at:

http://learnmem.cshlp.org/content/15/5/335.full.html\#ref-list-1

License

Email Alerting Receive free email alerts when new articles cite this article - sign up in the box at the Service top right corner of the article or click here. 